\title{
Developed Trigger Mechanisms to Improve Crush Force Efficiency of
}

\author{
Aluminium Tubes \\ ${ }^{1}$ V. Rai, ${ }^{1}$ H. Ghasemnejad1, ${ }^{2}$ J. W. Watson, ${ }^{1}$ J. A. Gonzalez-Domingo, ${ }^{1}$ P. F. Webb \\ ${ }^{1}$ Centre for Structures, Assembly and Intelligent Automation, Cranfield University, \\ MK43 0AL, UK \\ ${ }^{2}$ Cranfield Impact Centre (CIC), Cranfield University, MK43 OAL, UK
}

\begin{abstract}
.
This paper aims to investigate the effect of a trigger mechanism on the crush force efficiency of Aluminium tubular absorbers. Various trigger mechanisms such as cut-out holes, circumferential notch and end-fillet, were studied using the validated numerical model. Initially, tubes made of aluminium displayed better crashworthiness behaviour when compared with steel tubes based on numerical and experimental results. Then the trigger mechanism consisting of three cut-out holes was found more efficient than the ones with an end fillet and a circumferential notch based on a comparative study. According to these results, the developed trigger mechanisms have a significant change in crashworthiness performance of tubular absorbers. Crush force efficiency was doubled with the help of this trigger mechanism while stroke efficiency and specific energy absorptions were reduced by $4 \%$ and $15 \%$ respectively.
\end{abstract}

\section{Keywords.}

Crash; Trigger mechanisms; Circular tubes; Cut-out;

\section{Introduction}

According to World Health Organisation (WHO) report in 2015, around 1.25 million people lose their lives in road accidents each year costing 3\% of their GDP for most countries [1]. Thus, a safer transportation system, with enhanced crashworthiness is a need of the day. Crash tubes play a significant role in absorbing impact energy and reducing initial peak force to decrease acceleration levels experienced by passengers. As per theoretical calculations by Goes, around $6 \%$ to $7 \%$ reduction in fuel consumption can be achieved by decreasing the

\footnotetext{
${ }^{1}$ Corresponding Author: email: Hessam.Ghasemnejad@cranfield.ac.uk Tel.:+44 (0) 1234754395.

Centre for Structures, Assembly and Intelligent Automation, Cranfield University, MK43 OAL, UK.
} 
kerb weight by $10 \%$ in road transportation systems [2]. It generates a requirement for a lightweight structure for absorbing crash energy. Though composite materials are better suited for crash structures due to their lower weight; however, high cost and difficulties in recycling make them a less preferred option in passenger cars [3]. So, there is a need to improve the performance of metallic structures by ensuring weight reduction.

According to Jones, structural crashworthiness required to improve the safety of passengers in a transportation system, by sacrificing the structure to absorb impact energy. It is also required to maintain a survivable volume, limit forces and decelerations experienced by passengers [4]. Evaluation of crashworthiness performance can be carried out based on injury criteria to the occupants. Head injury criterion is one of the most used injury criteria as shown in Eq. (1) [5].

$$
\mathrm{HIC}=\underbrace{\max }_{t_{2}-t_{1}<\Delta}\left\{\left[\frac{1}{t_{2}-t_{1}} \int_{t_{1}}^{t_{2}} a(t) d t\right]^{2.5}\left(t_{2}-t_{1}\right)\right\}
$$

where $t_{1}, t_{2}$ are time intervals, $a(t)$ is acceleration at time $\mathrm{t}$ and $\Delta$ is a constant having dimension of time (15mS for euroNCAP) [6].

It is a common practice to place crash absorbers, which collapse in axial mode behind the car bumper [7] (see Figure 1).

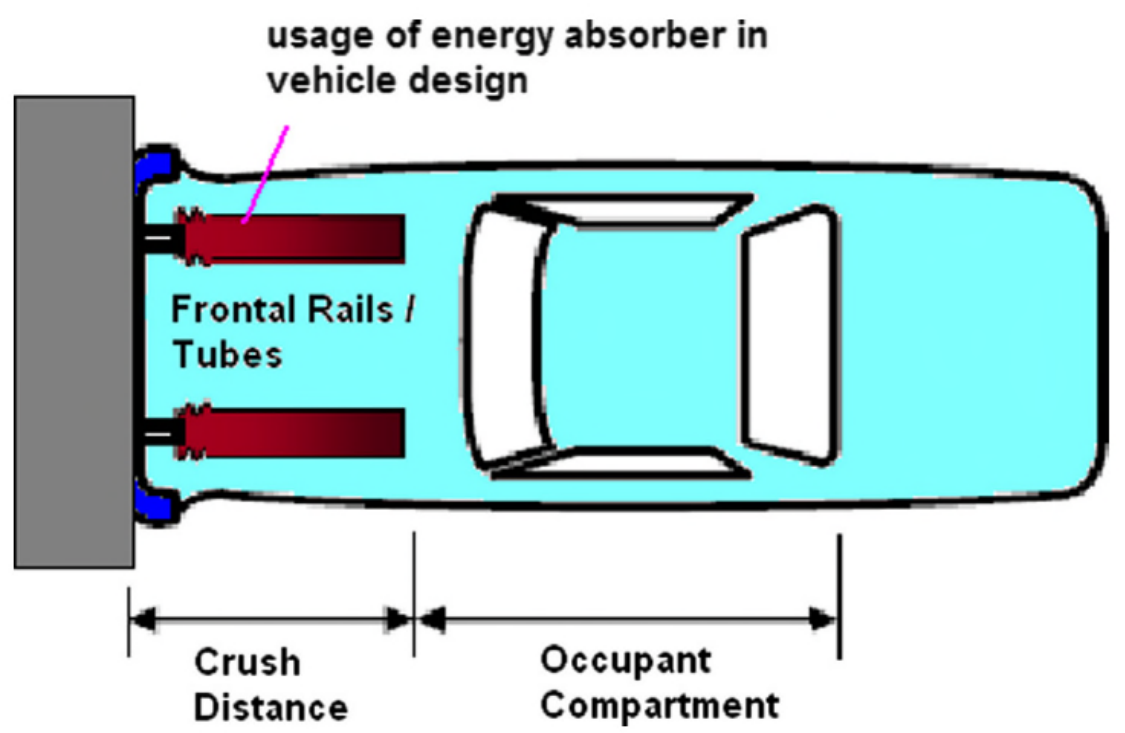

Figure 1 Location of the crash energy absorber in a car [7].

Figure 2 shows a typical load vs displacement graph of a thin-walled structure in axial compression. In the first stage, load reaches a maximum value to overcome the initial resistance of the tube due to elastic forces. Followed by fluctuations in the load about the 
mean crushing load in the second stage. In the final stage, the load increases drastically due to bottoming out of the tube.

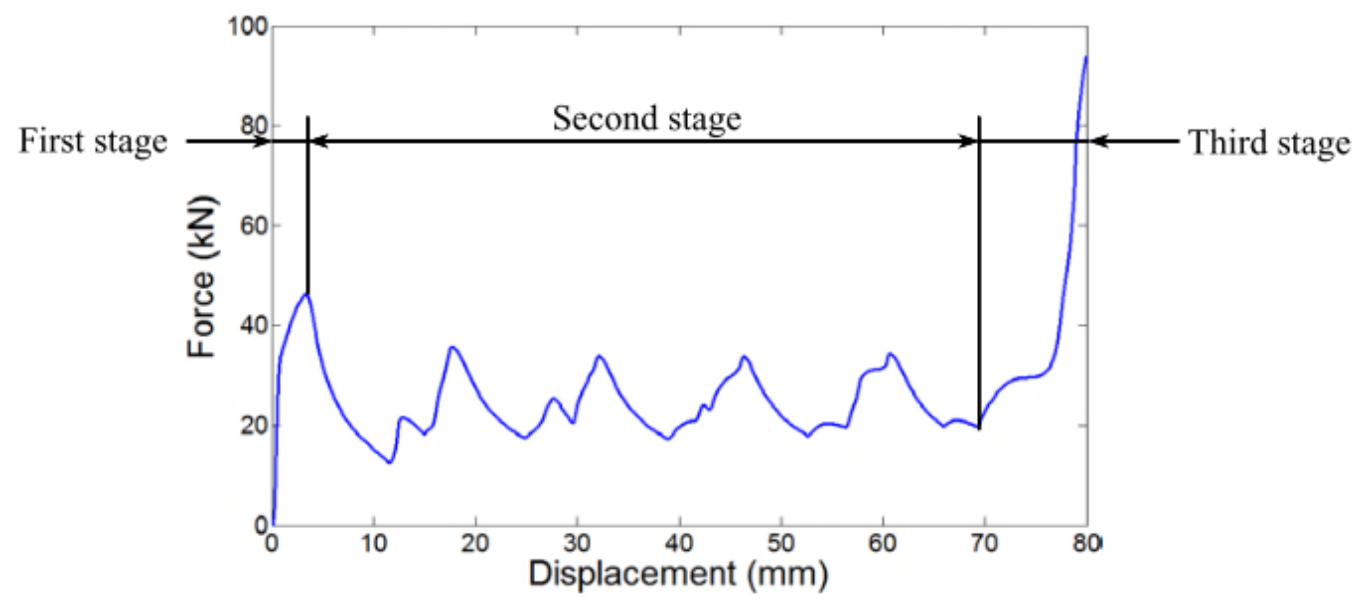

Figure 2 Typical load vs displacement curves of circular tubes in compression [8-9].

Saboori and Sadegh modelled human head numerically and applied different acceleration pulses having the same HIC value and observed the ones with peak occurring in later stage produces lower strains [10]. So, the crash tube which produces a peak force at a later stage is preferred.

Even though for lightweight applications aluminium and magnesium are being used increasingly, magnesium is not widespread in crash tubes due to its lower energy absorption as energy absorption is mainly due to cracking in the later [11].

Nia and Hamedani studied energy absorption of tubes made up of Al 3003 H12 numerically and experimentally under quasi-static conditions. Cross-sectional area, thickness and height were kept the same among samples. Circular tubes displayed better energy absorption among tested cross-sections (circular, square, rectangular, hexagonal, triangular) [12]. Similar studies we conducted by Santhosh Kumar and Manikandaraja numerically and obtained agreeing results of the previous study [13]. Tarlochan et al. conducted a comparative study using A36 steel in dynamic numerical simulation and concluded that a hexagonal profile is the best for impact followed by octagonal and circular [7]. Based on the above studies, it was decided to limit the study to crash tubes with a circular cross-section.

Four types of deformations are possible in circular tubes subjected to axial compression loads depending upon the ratio of the diameter to the thickness and the diameter to the height. They are, a) Axisymmetric concertina or ring mode, b) Non-axisymmetric diamond, c) Mixed mode, and d) Euler type buckling or global buckling. 
Axisymmetric concertina displays a higher energy absorption in comparison to the nonaxisymmetric diamond mode [14]. The axisymmetric mode is more stable and fewer chances of changing the collapse mode to Euler buckling during crushing [15]. Euler type of buckling has very low energy absorption, and the consequences are disastrous. So, it must be avoided in crashworthiness [8].

Among all crushing modes, axial progressive crushing has higher energy absorption due to the involvement of higher plastic deformations. It was observed that initial peak force is much higher than the subsequent ones and this leads to lower CFE. So, to increase CFE, it is required to introduce small imperfections called trigger mechanism [16]. Gupta conducted experiments on steel and aluminium tubes with and without holes drilled and concluded that tubes with holes deform in Euler buckling at a higher L/D ratio in comparison to the ones without [17]. In general, a trigger mechanism is used to, a) initiate a specific collapse mode, b) stabilise collapse process and c) to reduce initial peak load in case of an axial collapse.

Various researchers studied different types of imperfections by using them as trigger mechanisms. Mostly they are modifications in geometry or introduction of cut-outs. Gupta studied the effect of two holes at mid-height experimentally on circular tubes and observed a reduction in peak load [17 - 18]. A further reduction in initial peak force with an increase in the hole diameter was observed. Toda conducted experiments on buckling loads of cylinders with two opposite holes at the mid-height and observed that there is no reduction in buckling load up to a particular diameter and then buckling load decreases with increase in hole diameter [19]. Chiu and Jenq conducted experiments on aluminium square tubes with circular, elliptical and slotted holes and observed a decrease in initial peak force [20]. Montazeri et al. used an array of circular holes as trigger mechanism and compared the same mechanism with the grooved trigger [21].

Zhang et al. used pulling strips on the tube end to ensure notches are formed during the impact and observed more than $30 \%$ reduction in the initial peak [22]. However, there was no reduction in energy absorption. Effect of the number of strips was studied and observed the most stable crushing mode when the number of strips is 3 leading to a diamond mode of deformation. Singace and El-Sobkey studied the crushing behaviour of corrugated tubes and found an excellent crash response when corrugation depth was optimised [23]. Chen and Ozaki studied parameters influencing circumferential strain on corrugated tubes and concluded that corrugation wavelength, the amplitude of corrugation and radius of the cylinder are the ones influencing the most [24]. A circumferential notch type trigger mechanism was studied numerically and experimentally by Kafer et al. [25]. Yiru et al [26] studies a reduction in peak force with this type of trigger. Double-coupled triggers further weaken triggered regions 
to reduce the initial peak while triple-coupled triggered tubes improve Energy-Absorption (EA). Jiang et al [27] proposed the wedge-trigger, two types of $W$-triggers and bevel-triggers with hybrid angles to achieve better crashworthiness of composite waved beam. the effect of various types of triggers is investigated for GFRP composite crash boxes. Hussain et al [28] investigated a comparative study of variation of peak forces, energy absorbed, S.E.A (specific energy absorbed) with the variation of triggers for crash box. The effect of various types of triggers was investigated for GFRP composite crash boxes. Force vs. displacement curves were then plotted for each case providing detailed insights into the force variation during deformation.

This paper aims to investigate the effect of the new developed trigger mechanisms on tubular crash structures made of aluminium material. A numerical model will be developed to simulate an impact scenario of crash tubes and various trigger mechanisms will be studied by using the validated numerical model. Results of the optimum trigger mechanism will be validated by experiment obtaining agreeable results. It will be shown that crush force efficiency increases with the help of a trigger mechanism while stroke efficiency and specific energy absorptions reduce by $4 \%$ and $15 \%$ respectively. Finally, this paper will exclusively investigate the effect of trigger mechanism on the improvement of crush force efficiency (CFE) additional to the available literature.

\section{Experimental studies}

The impact test was perfomed with the impact mass of $671 \mathrm{~kg}$ moving at $7 \mathrm{~m} / \mathrm{s}$. Aluminium 6063 T6 and steel E325 tubes were chosen for the study. Dimensions and material properties of chosen tubes are given in Table 1 and Table 2 respectively.

True stress strain curves for both the materials are also shown in Figure 3. Two tubes were chosen to ensure adequate factor of safety and suffcient deformation of the tube.

Table 1 Tube dimensions of Aluminium and Steel crash absorbers.

\begin{tabular}{lcccc}
\hline Properties & \multicolumn{2}{l}{ Aluminium 6063 T6 } & \multicolumn{2}{c}{ Steel E235 } \\
\hline Length & 600 & $\mathrm{~mm}$ & 600 & $\mathrm{~mm}$ \\
Diameter & 76.2 & $\mathrm{~mm}$ & 75 & $\mathrm{~mm}$ \\
Thickness & 1.626 & $\mathrm{~mm}$ & 1.5 & $\mathrm{~mm}$ \\
\hline
\end{tabular}


Table 2 Material properties of Aluminium and Steel matals [40].

\begin{tabular}{lllll}
\hline Properties & \multicolumn{3}{l}{ Aluminium 6063 T6 } & Steel E235 \\
\hline Yield Stress & 206.92 & $\mathrm{MPa}$ & 218 & $\mathrm{MPa}$ \\
Young's modulus & 68.9 & $\mathrm{GPa}$ & 210 & $\mathrm{GPa}$ \\
$\begin{array}{l}\text { Poisson's ratio } \\
\text { Tangent modulus }\end{array}$ & 0.33 & & 0.3 & \\
$\begin{array}{l}\mathrm{D} \quad \text { (intensity of plastic } \\
\text { strain velocity) }\end{array}$ & $9.40 \mathrm{e} 10$ & $\mathrm{MPa}$ & 594.7 & $\mathrm{MPa}$ \\
$\begin{array}{l}\text { q (material sensitivity to } \\
\text { plastic strain velocity) }\end{array}$ & 9.55 & - & 114 & /s \\
\end{tabular}

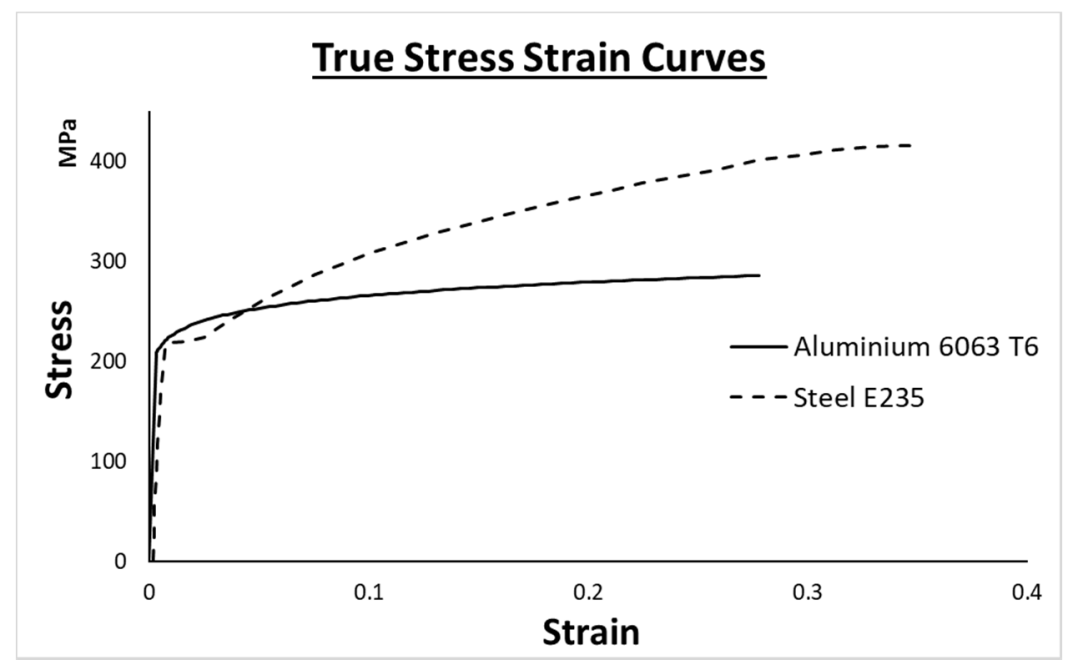

Figure 3 True stress-strain curves of aluminium 6063 T6[26] and steel E235 [29].

Performance of crash tubes can be compared mainly by using three parameters [9]. They are crash force efficiency, stroke efficiency and specific energy absorption. A ratio between mean crushing force and the maximum initial collapse force is known as crush force efficiency (CFE) and can be calculated by using Eq. 1. A lower crash force efficiency may lead to higher deceleration levels on the passengers in the initial stage and hence a potential higher HIC value. 


$$
\mathrm{CFE}=\frac{\text { Mean crushing force }}{\text { Maximum initial collapse force }}
$$

Stroke efficiency (SE) can be calculated by using Eq. 2. A crash absorber with higher stroke efficiency requires a lower initial length of the absorber and hence better space utilisation.

$$
\mathrm{SE}=\frac{\text { Stroke length at bottoming out }}{\text { Initial length of the absorber }}
$$

Specific energy absorption (SEA) is given by Eq. 3. A design with better SEA ensures lower weight and better fuel economy.

$$
\mathrm{SEA}=\frac{\text { Energy absorption }}{\text { Mass of the absorber }}
$$

Impact testing facilities at Cranfield Impact Centre were used to conduct all the crash tests. The test setup consists of an impactor, a pneumatic system to accelerate the impactor to a predetermined velocity, and a holding fixture, which is fixed to the wall rigidly as shown in Figure 4 and 5 . An accelerometer was fitted on the impactor to measure acceleration and to obtain impact force. Asensor positioned just before impact was used to confirm the velocity of impact. Data from sensors was collected at a rate of $20 \mathrm{kHz}$. Mass of the impactor was $671 \mathrm{~kg}$, and it was set to impact at $7 \mathrm{~m} / \mathrm{s}$ on two crash tubes fixed on the wall by using a holding fixture.

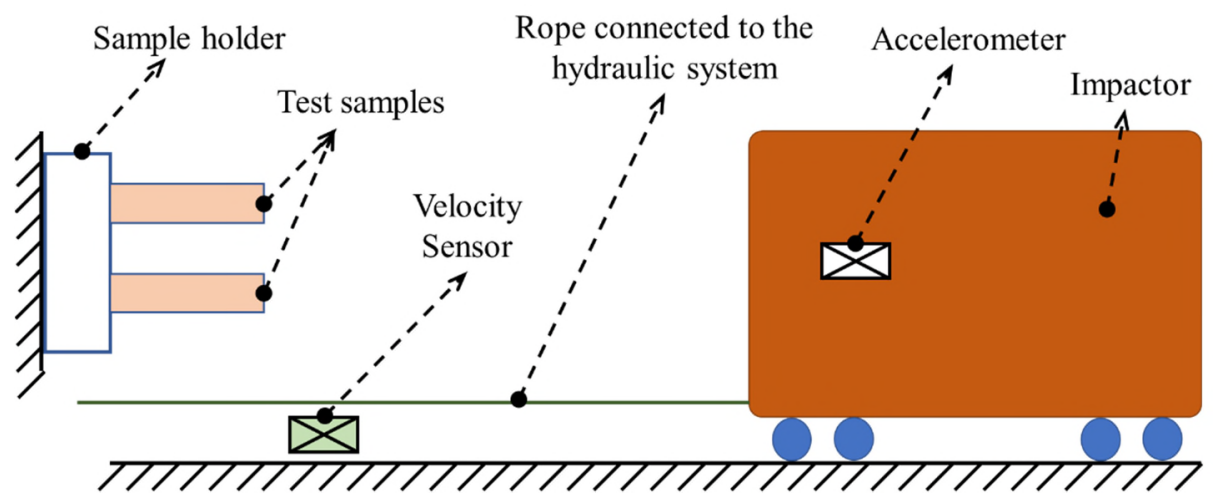

Figure 4 Schematic diagram of the test setup.

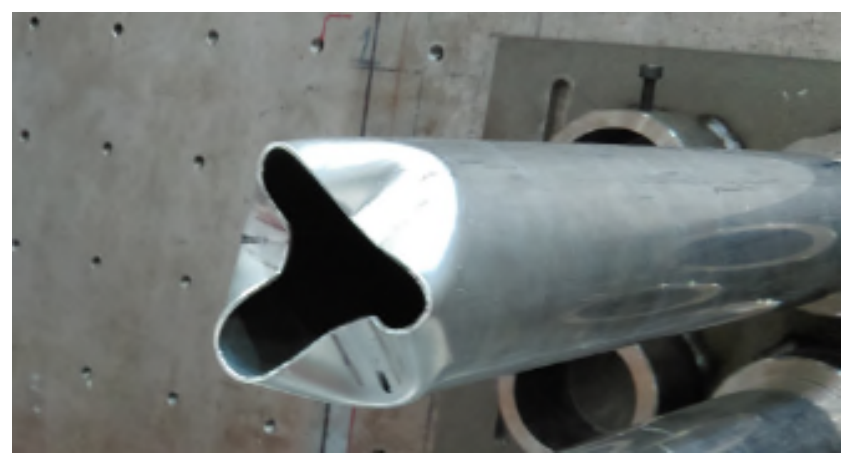

Figure 5 Tubes with three end notches as a trigger mechanism (Dimensions given in Table 1). 
The aluminium tube deformed in a diamond mode with three circumferential lobes with a mean force of $63 \mathrm{kN}$ and total deformation was $262 \mathrm{~mm}$. The collapse process was very stable as the same deformation pattern continued throughout. A lower initial peak force was observed due to the trigger mechanism. A force vs crush distance diagram has been shown in Figure 6 with CFC 60 filter (defined as a method to normalise fluctuations in force - displacement curve) to reduce noise.

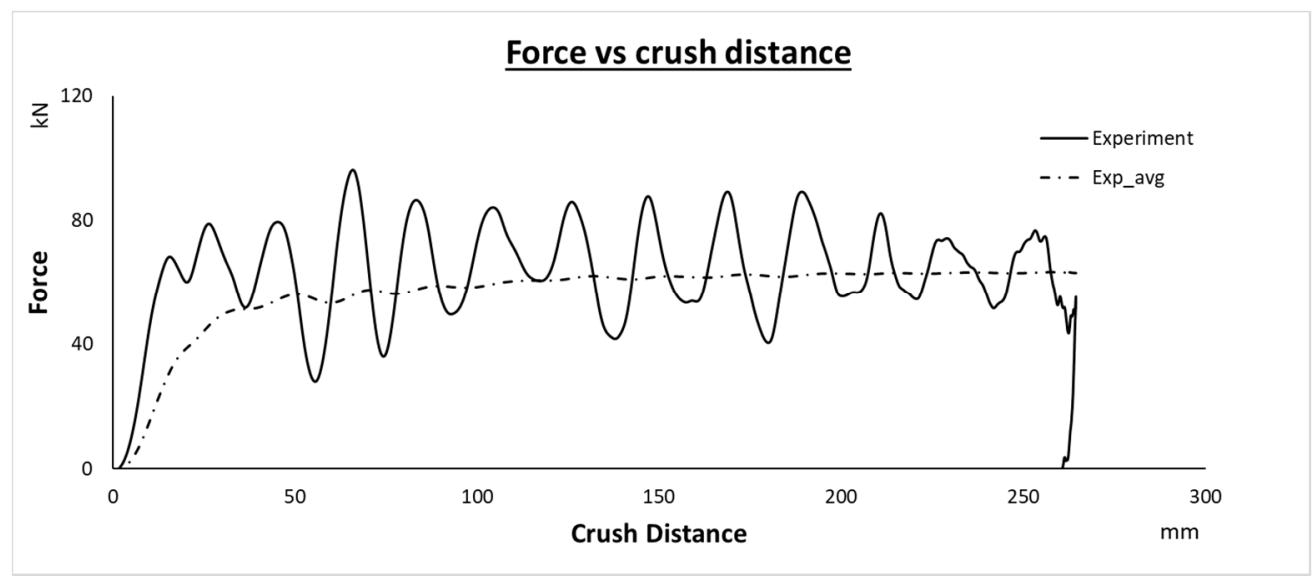

Figure 6 Force vs Crush distance diagram for aluminium 6063 T6 tube.

Deformation pattern of the steel tube was similar to aluminium tubes as both deformed in a diamond mode with three circumferential lobes (see Figure 7). Mean crushing force of the steel was $126 \mathrm{kN}$ which is almost double in comparison with aluminium tubes with mean crushing force of $63 \mathrm{kN}$. Force vs crush distance diagram for the steel tube has been shown in Figure 8 with CFC 60 filter to reduce noise.
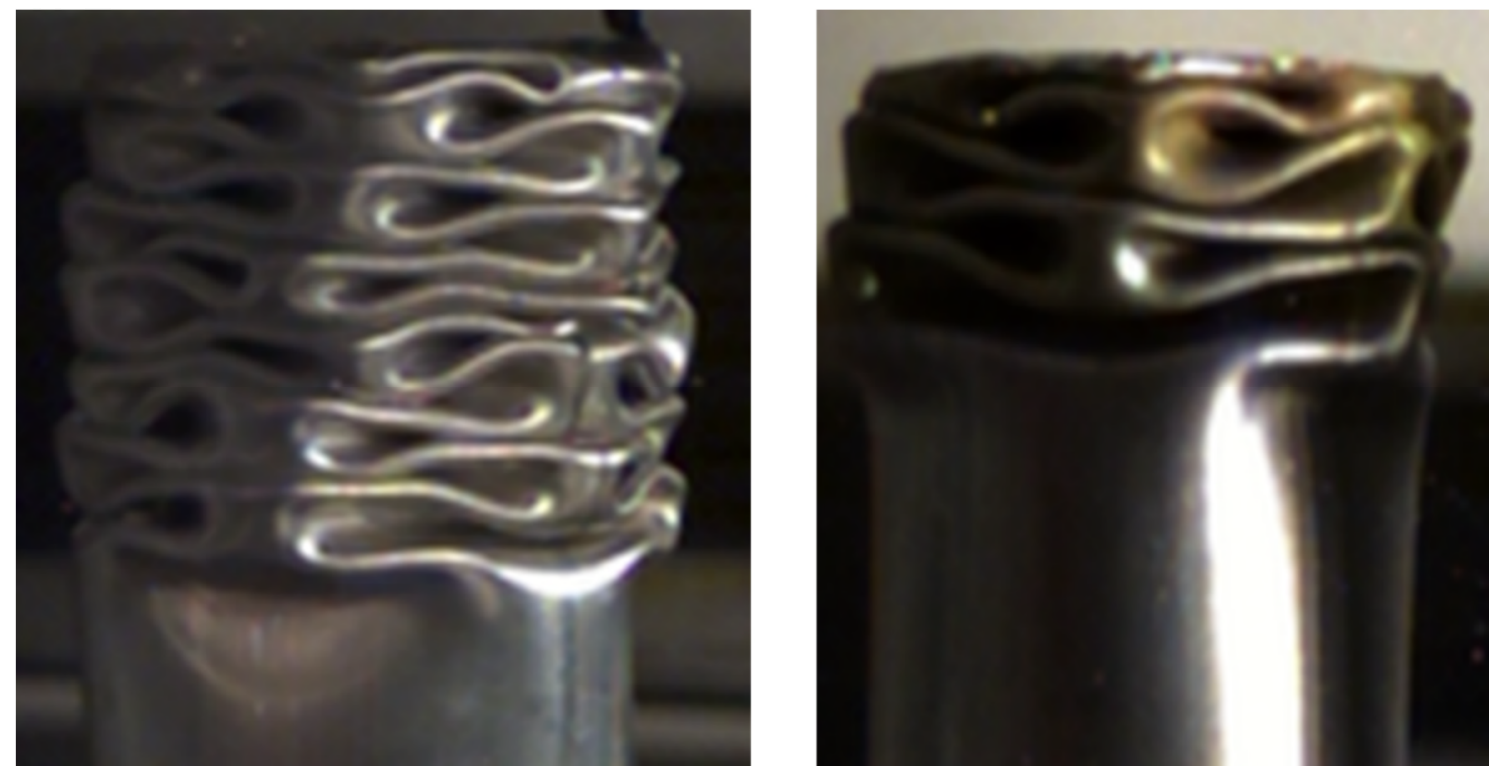

Figure 7 Deformed shapes of aluminium 6063 T6 and steel E235 tubes (Dimensions given in Table 1). 


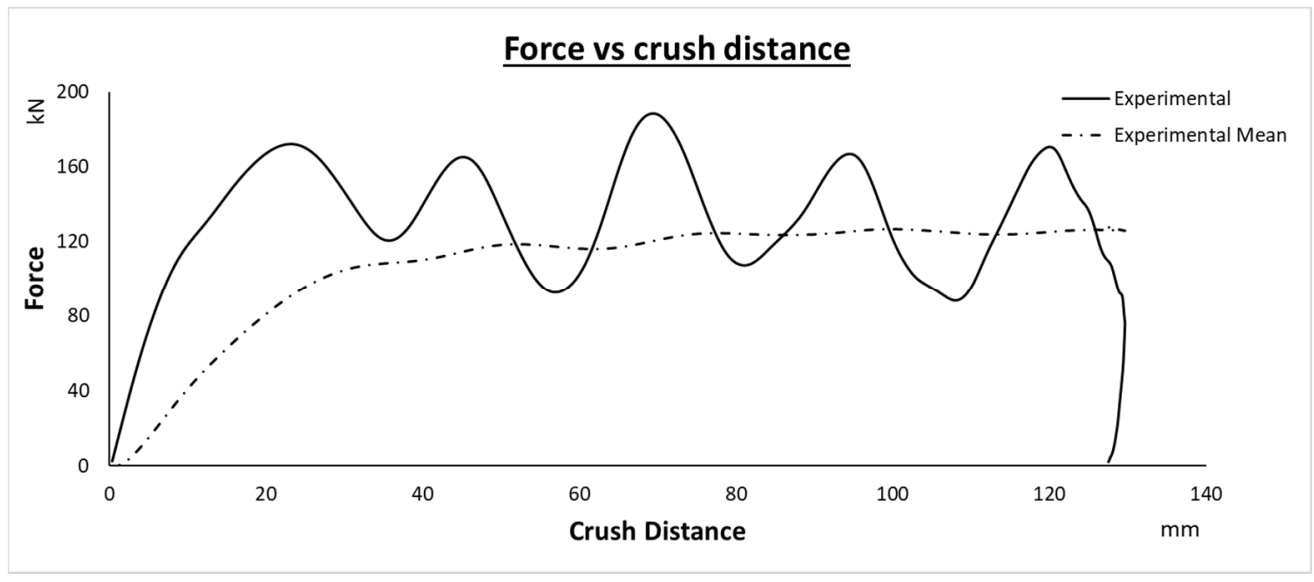

Figure 8 Force vs Crush distance diagram for Steel E235 tube.

In Figure 9, it can be clearly observed that crash tubes made of aluminium are superior in comparison with steel tubes in the compared performance indicators.

\section{Crashworthiness performance indicators}

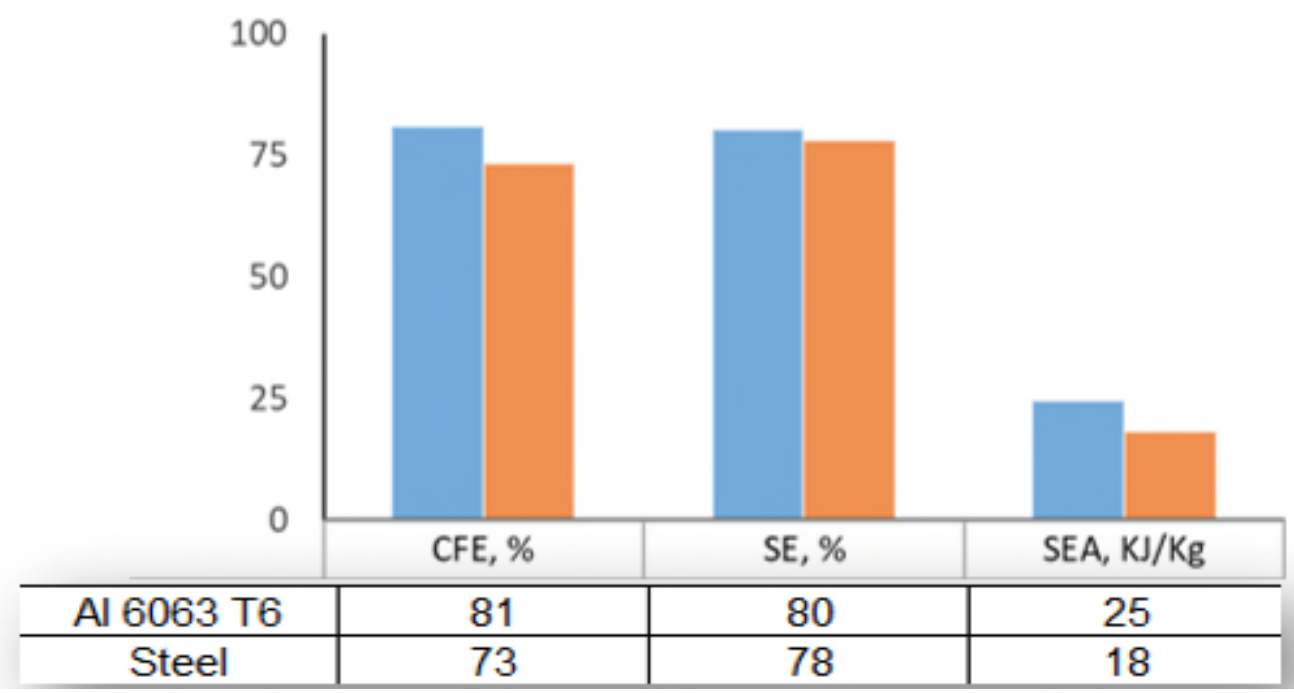

Figure 9 Performance indicator comparison for aluminium6063 T6 and steel E235.

\section{Numerical studies}

The crash test set up was modelled by using LS-PrePost and was solved using the explicit solver of LS-Dyna. Belytschko-Tsay shell elements with four nodes were used to model the cylinder mid-surface [20]; [30]; [31]; [32]. A 2.5mm mesh size and five throughthickness integration points [8]; [33]; [34] were chosen based on mesh sensitivity analysis in the literature. The material model of Piecewise linear plasticity (MAT24 in LS-Dyna) was chosen along with strain rate sensitivity parameters [4]; [9]; [35]. A constant stress solid element with $10 \mathrm{~mm}$ element size was used to model the impactor. Impactor was assumed to be made of steel with Young's modulus 210GPa and Poisson's ratio 0.3. The density of 
the same was artificially modified to obtain the mass of the impactor. Figure 10 shows a schematic diagram of the numerical model used for the study.

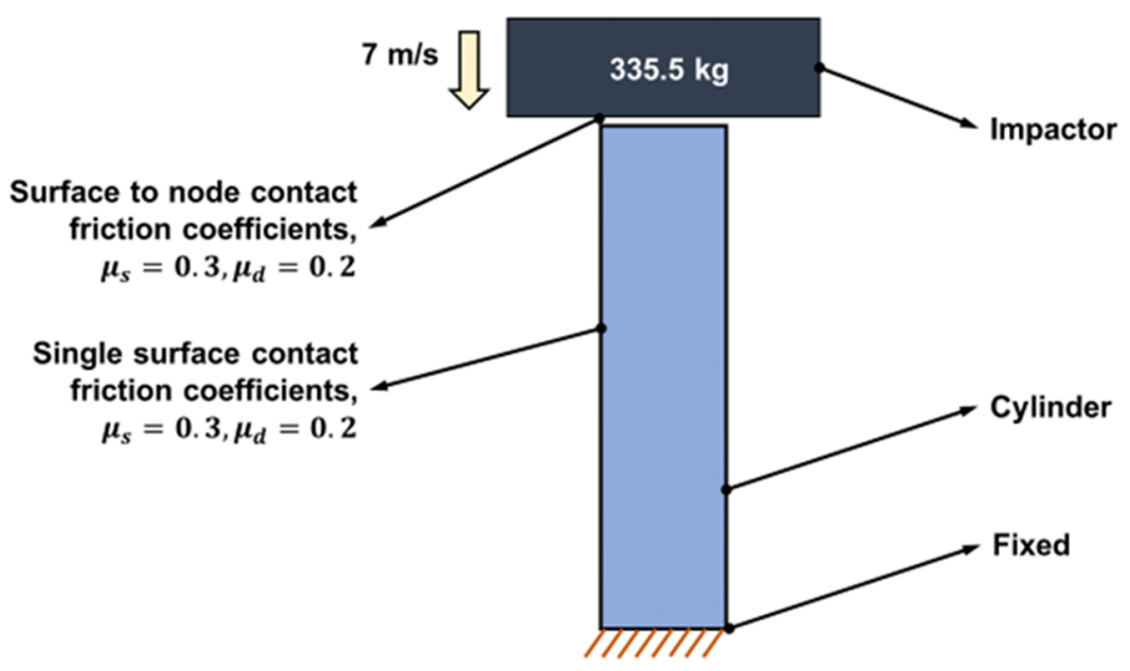

Figure 10 Schematic diagram of the numerical model.

A constraint in all degrees of freedom was applied on nodes at the bottom end of the cylinder and nodes of the impactor were fixed in all degree of freedom except in the direction of impact. An initial translational velocity of $7 \mathrm{~m} / \mathrm{s}$ in the direction of impact applied on the impactor. Less than $1 \mathrm{~mm}$ distance was kept between the impactor and the crash tube for better computational efficiency. An automatic surface to node contact applied between impactor and the cylinder; an automatic single surface contact applied for the cylinder surface. Both the contacts were with Coulomb friction coefficients 0.3 and 0.2 for static and dynamic frictions respectively [36 - 39].

Since the trigger mechanism was made by using a hand tool, it was difficult to replicate the geometry in a CAD tool. In order to obtain acceptable results, it is essential to have an accurate geometrical model for the crash simulation. Therefore, simulations were carried out in two stages. In the first stage, forming simulations were carried out to obtain tubes with sufficiently accurate trigger mechanism geometry, and then it was used as an input geometry for the crash simulation carried out in the second stage.

Constant stress solid elements of element size $2 \mathrm{~mm}$ were used to model the forming tool. The geometry of the forming tool was decided based on the actual tool dimensions. The width of the actual tool is $12 \mathrm{~mm}$, with $2 \mathrm{~mm}$ chamfers on the forming edges, and hence a width of $10 \mathrm{~mm}$ was chosen for the simulations. To obtain accurate geometry of the trigger a fine mesh with a size of $1.25 \mathrm{~mm}$ was chosen near the trigger and a mesh size of $2.5 \mathrm{~mm}$ 
on remaining areas as shown in Figure 11. The bottom end of the tube was fixed rigidly in all degree of freedoms. All three forming tools were used in simulations simultaneously to ensure balancing of the offset forces. To easy application of boundary conditions on tools, three local coordinate systems were created by choosing the respective bottom edge of tools lying inside the tube as the $x$-axis and aligning the z-axis to the global one. The bottom edge of the tool which lies inside the tubes was chosen as a rotation axis for the tool by fixing all nodes of the same in all degrees of freedom except the rotation along the $x$-axis on their respective local coordinate system. Angular rotation of 65 degrees was applied over a period of 0.05 seconds at a constant angular velocity to obtain desired geometry of the notch. Automatic node to surface contact was used between tools and the cylinder with a coulomb friction coefficient of 0.3 . However, no contact was applied among tools to ensure smooth operation of 3 tools simultaneously.

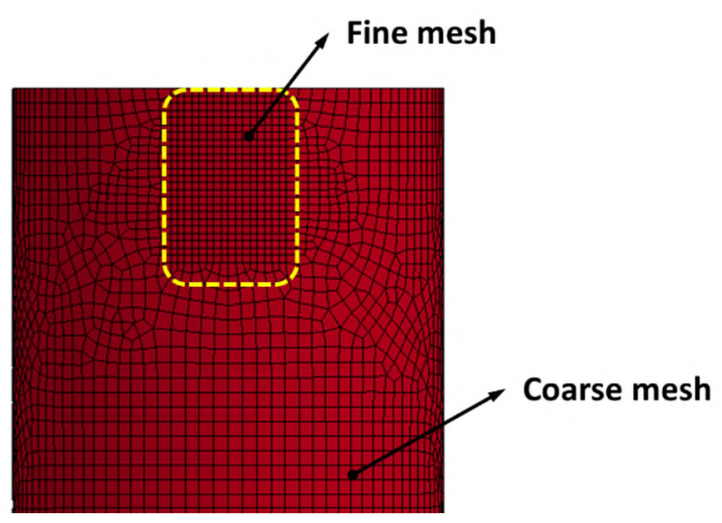

Figure 11 Meshing of the tubes near the trigger.

The numerical model set up in the previous section was solved by using the explicit solver of the LS-Dyna and the deformed shape obtained has been shown in Figure 12. An optimum shape of the notches was obtained when overlap between the cylinder and the tools was $25 \mathrm{~mm}$, even though in the actual minimum overlap is $30 \mathrm{~mm}$ before forming. It is due to the sliding of the tool during forming in actual condition. 

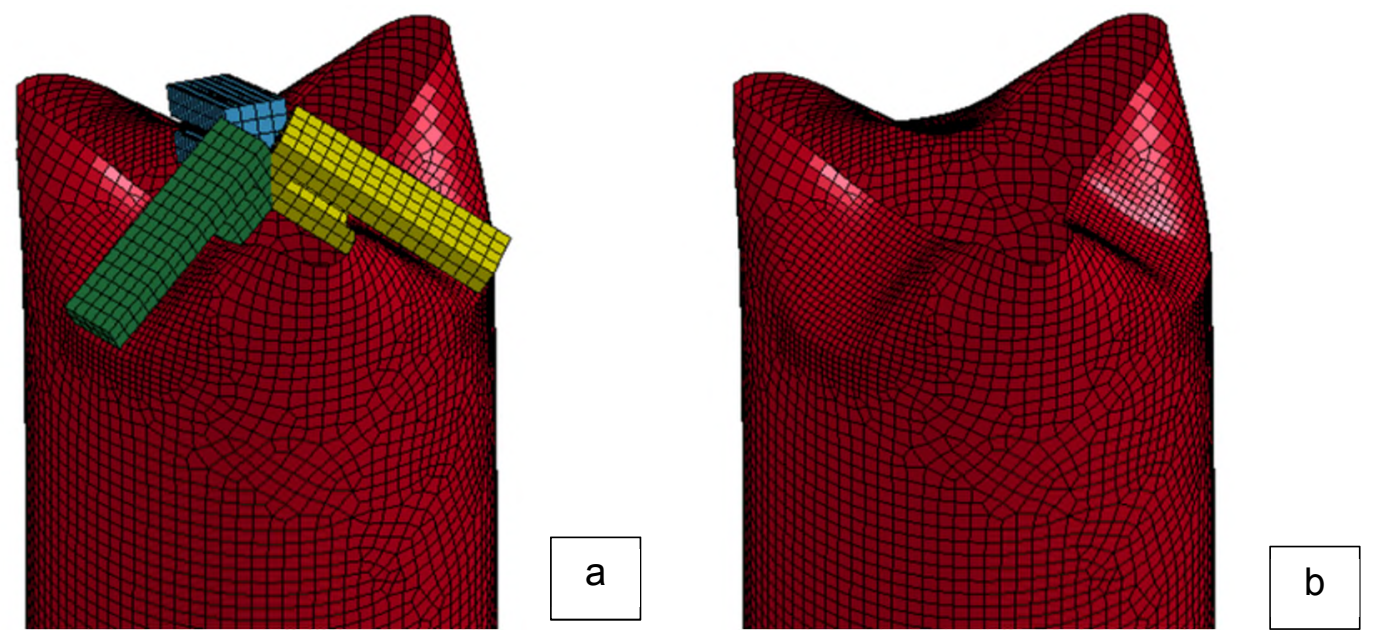

Figure 12 Cylinder after forming notches, a) with and b) without tools.

Element and nodal results of the cylinder were taken out for the next simulation. However, strain hardening and thinning parameters were not considered due to time constraint and simple nature of the problem.

In numerical impact simulation, crash tube deformed in a diamond mode with three circumferential lobes which is the same as experimental results. Force - crush distance plot along with the comparison to experimental results has been shown in Figure 13. There was a good match between the experimental and numerical results except in the initial peak region. It can be due to imperfections present in the actual test case. Mean crushing force, crush distance and deformed shape predicted in the numerical simulation is close to the experimental one and hence the numerical simulation is validated (see Figure 14).

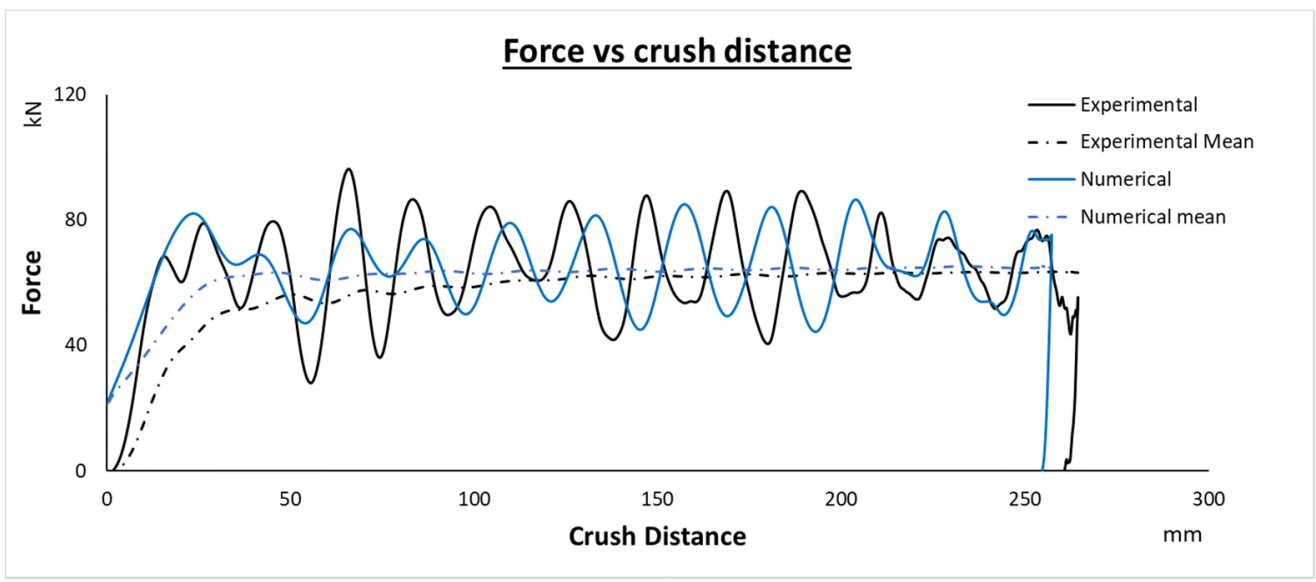

Figure 13 Force vs crush distance plots for aluminium 6063 T6 tube. 

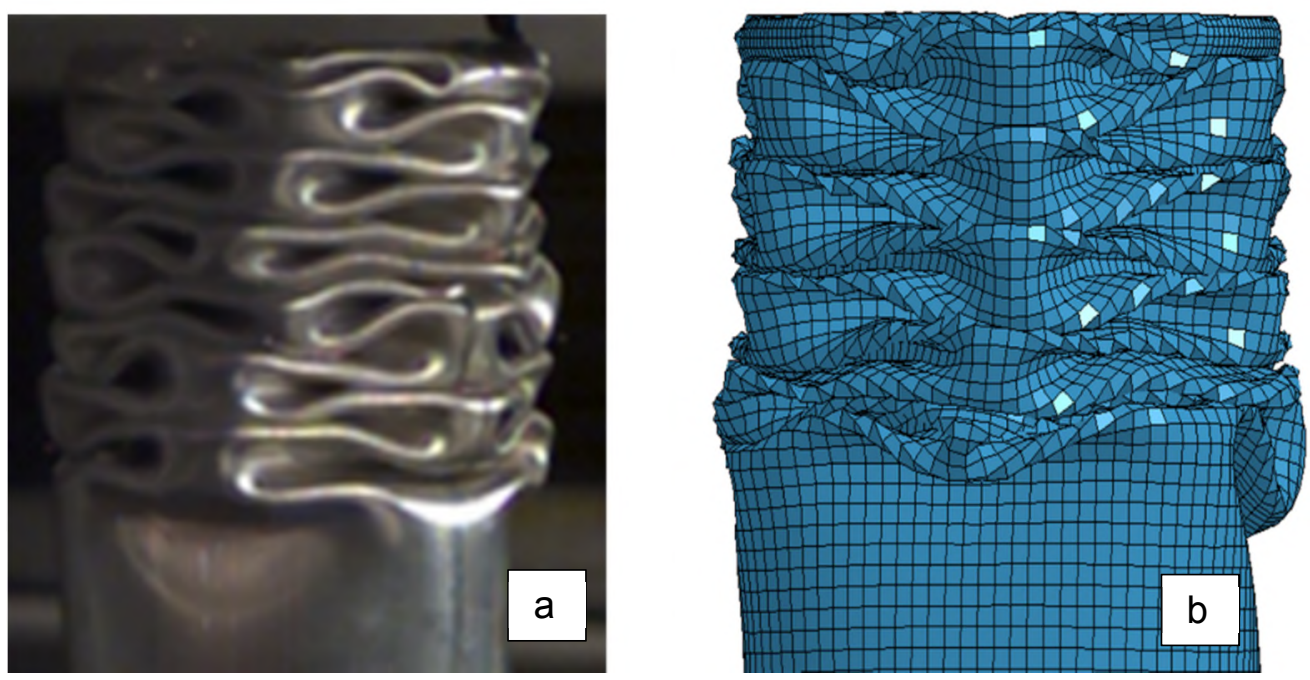

Figure 14 Deformed shape of aluminium 6063 T6 tube in a) experiment and b) numerical simulations.

\subsection{Crash tubes without trigger mechanism}

According to the FE results, the aluminium tube crushes in concertina mode $(\mathrm{CM})$, and then it turned to diamond mode (DM) with four circumferential lobes as predicted in previous section. The force vs crush distance diagram is shown in Figure. A high initial peak of $189 \mathrm{kN}$ observed followed by alternating forces about a mean value of $77 \mathrm{kN}$. Crush distance at the end of impact was $214 \mathrm{~mm}$. The pattern of alternating force differs significantly for concertina mode (CM) and diamond mode (DM) (see Figures 15 and 16). It is mainly due to the different energy absorption mechanisms of these two modes.

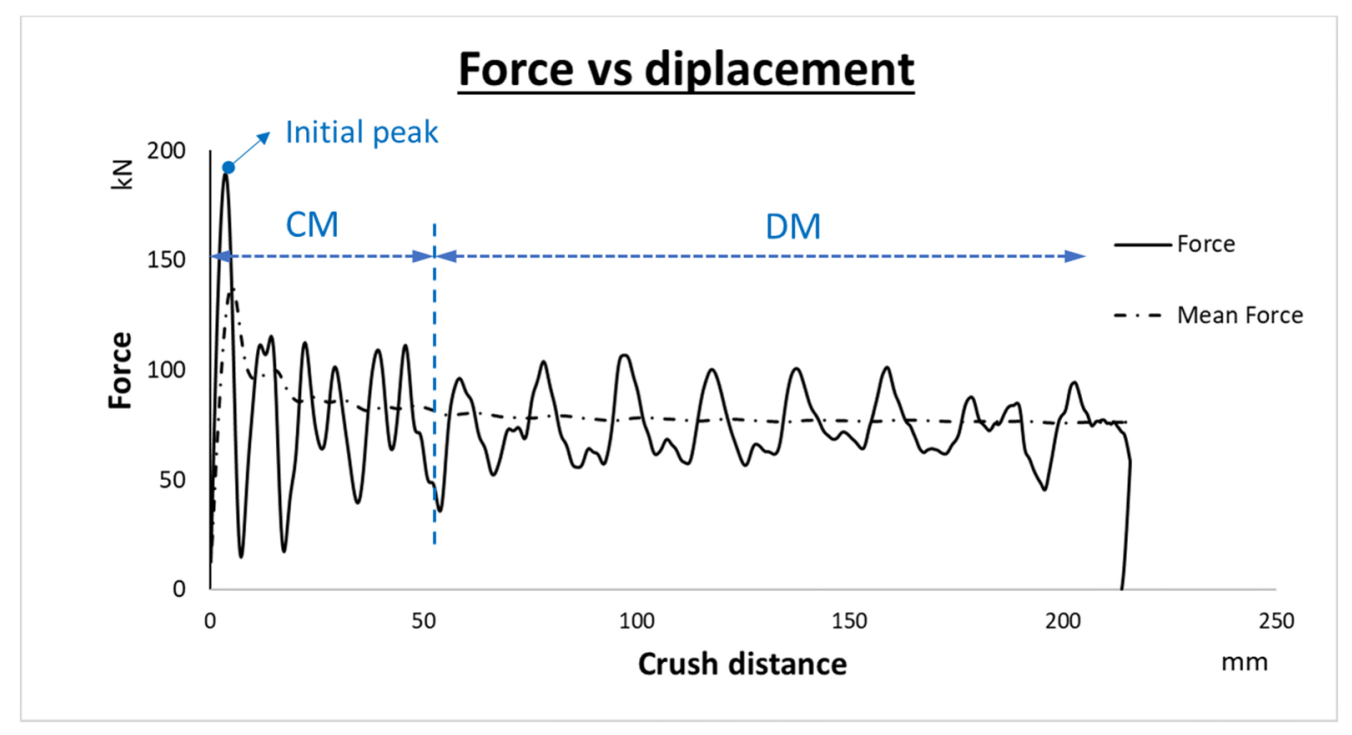

Figure 15 Force vs displacement for aluminium 6063 T6 tube without a trigger mechanism. 


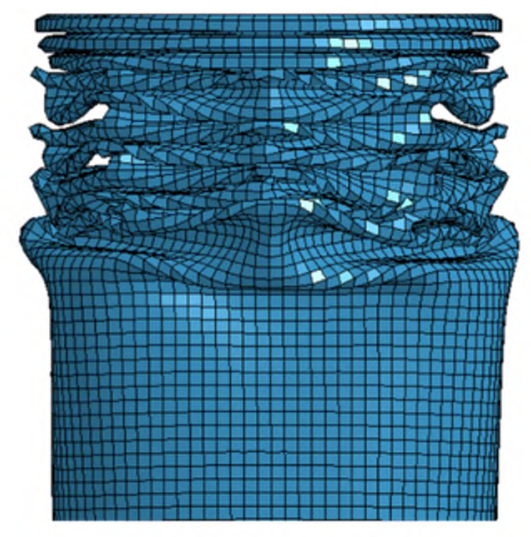

Aluminum $6063 T 6$

Figure 16 Deformed shape of Aluminium tube without a trigger mechanism.

Initial peak force is higher than mean force, which is due to the absence of a buckling initiator for the first lobe. For the subsequent lobes, deformations in the previous lobe act like a buckling initiator. The initial peak also may lead to a higher acceleration level on passengers or the payload during a crash event. Therefore, it would be advantageous to reduce the level of force transmitted from a crush tube to the occupant compartment.

\subsection{Crash tubes with trigger mechanisms}

\subsubsection{Cut-out hole trigger mechanism}

By taking inspiration from the trigger mechanisms used in the literature, few concepts have been developed and investigated in this study. Cutouts in the form of holes and slots were located near the impact end to decrease the required plastic hinge moment to form the first fold. Subsequent folds were expected to obtain crash initiation from the deformation created by the preceding fold (see Figure 17).

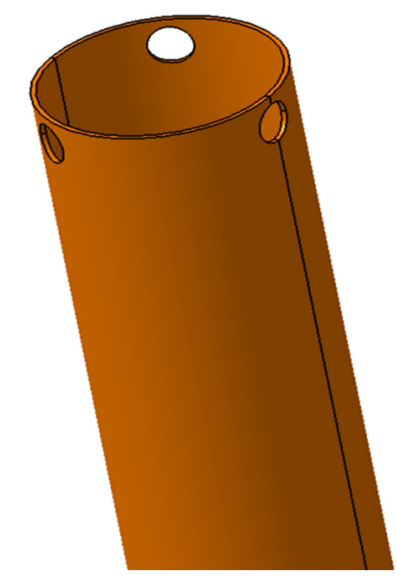

Figure 17 Circular cutouts around the tube absorber. 
The effect of hole diameter on the trigger mechanism was studied by placing three and four holes at the impact end such that the distance between their centres and the impact end was $10 \mathrm{~mm}$. It was ensured that at least ten elements were presented around the hole to capture the effect of stress concentration. A SAE600 filter was used on force vs displacement curves to reduce the noise. A plot of Initial peak force and mean crushing forces concerning hole diameter is shown in Figure 18.

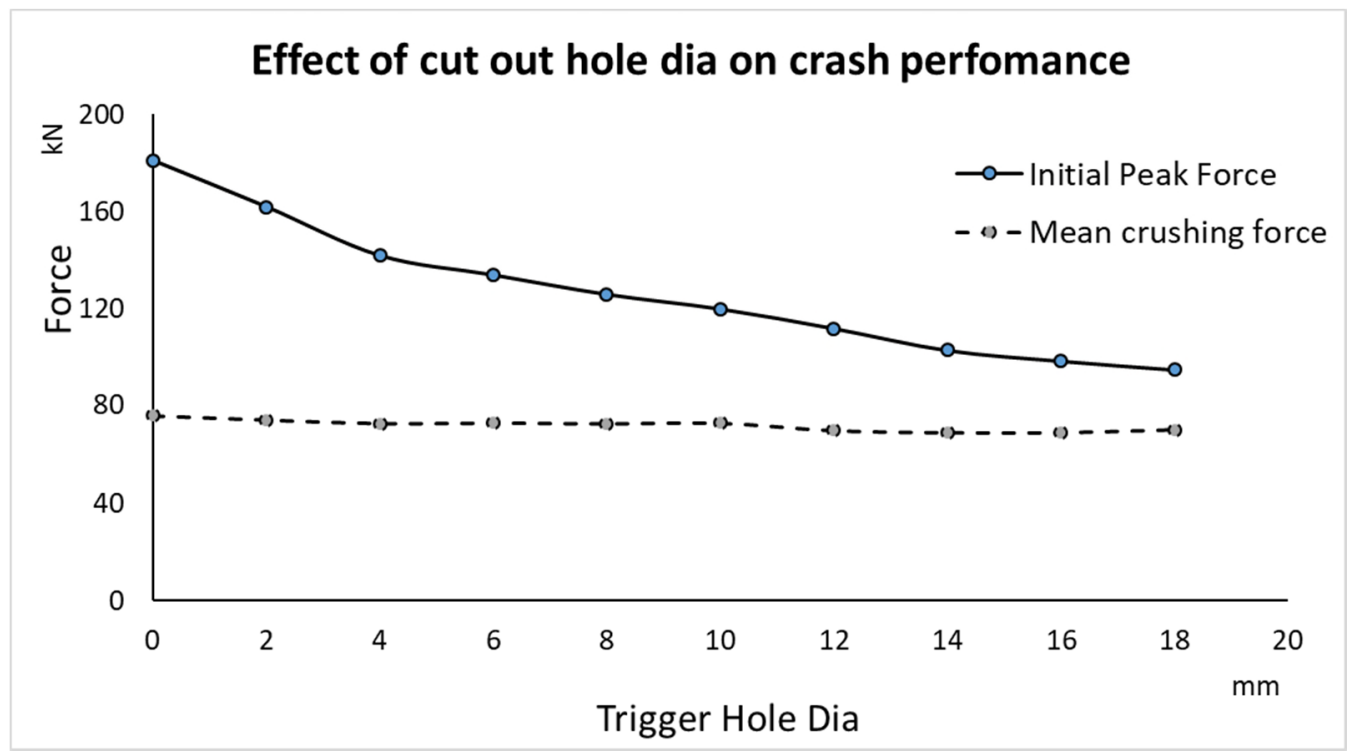

Figure 18 Initial peak force and mean crushing force vs cut out hole diameter.

As the diameter of the hole increased, the initial peak force decreased sharply up to $14 \mathrm{~mm}$ in diameter and stabilises later. This trend was similar to the one suggested by Toda [19]. However, the value of the diameter was entirely different due to the difference in hole position as Toda's results were based on the holes at mid-height. Even though mean crushing force decreased with an increase in diameter, the decrease is almost negligible, and hence a flat pattern is observed on the graph. Based on these studies, it is advised to select a diameter above $14 \mathrm{~mm}$.

The effect of the location of cut out holes was studied by placing four $14 \mathrm{~mm}$ diameters circumferentially. The distance between the centre of the hole and impact end was varied, and numerical simulations were carried out for every single case. Peak forces and mean forces were plotted against the location of the cutouts as shown in Figure 19. 


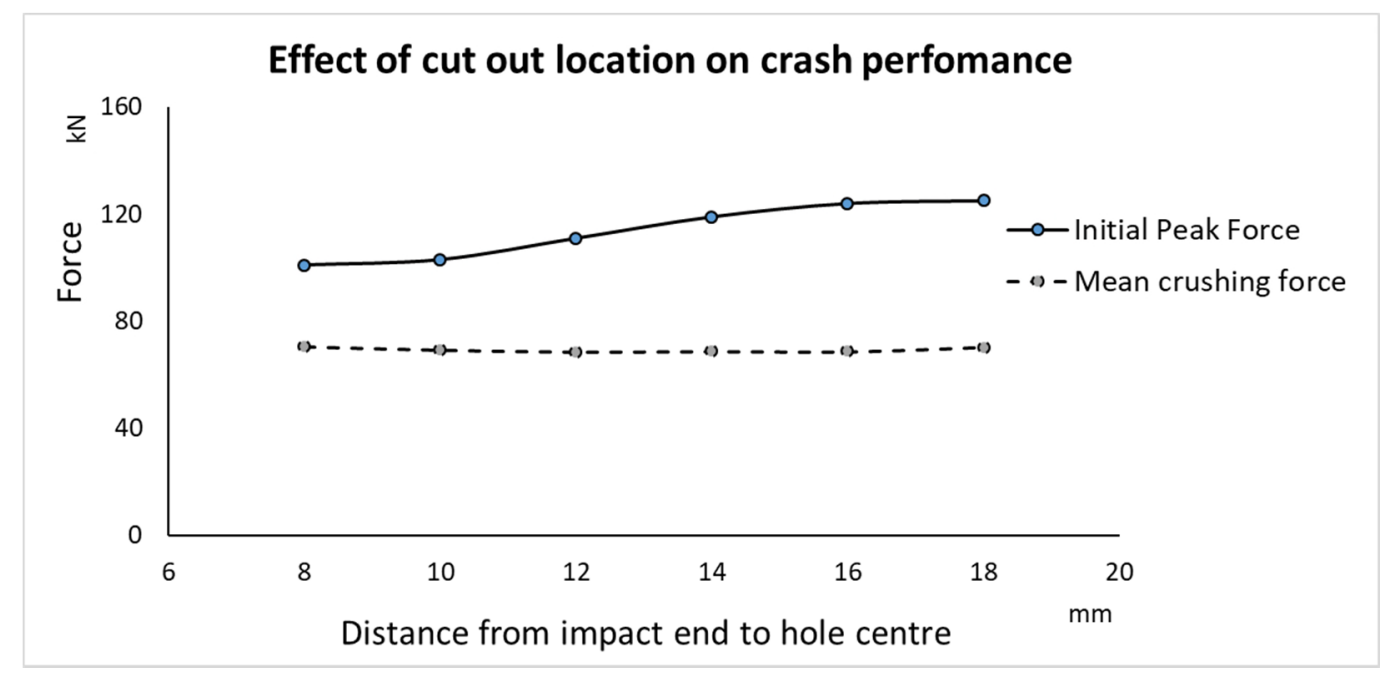

Figure 19 Initial peak force and mean crushing force vs location of cut out hole centre.

It is clear from Figure 20 that as the cutout moves closer to the impact end, initial peak force decreases. However, this effect was predominant when the cut out nears the impact end. It is mainly due to the buckling initiation mechanism. In general, during the impact, the top end of the tube moves inward to initiate the folding which causes compressive stresses on the cylinder surface as shown in Figure 20. By moving the cut out closer to the impact end, buckling strength of the cylinder at the impact end reduces and makes it easy to initiate local buckling and hence the folding. Mean crushing force remained almost constant for all locations and hence no significant effect on energy absorption capacity. It is evident that when the distance between impact end and centre of $14 \mathrm{~mm}$ circular cut-out is less than $10 \mathrm{~mm}$ a lower peak can be obtained.
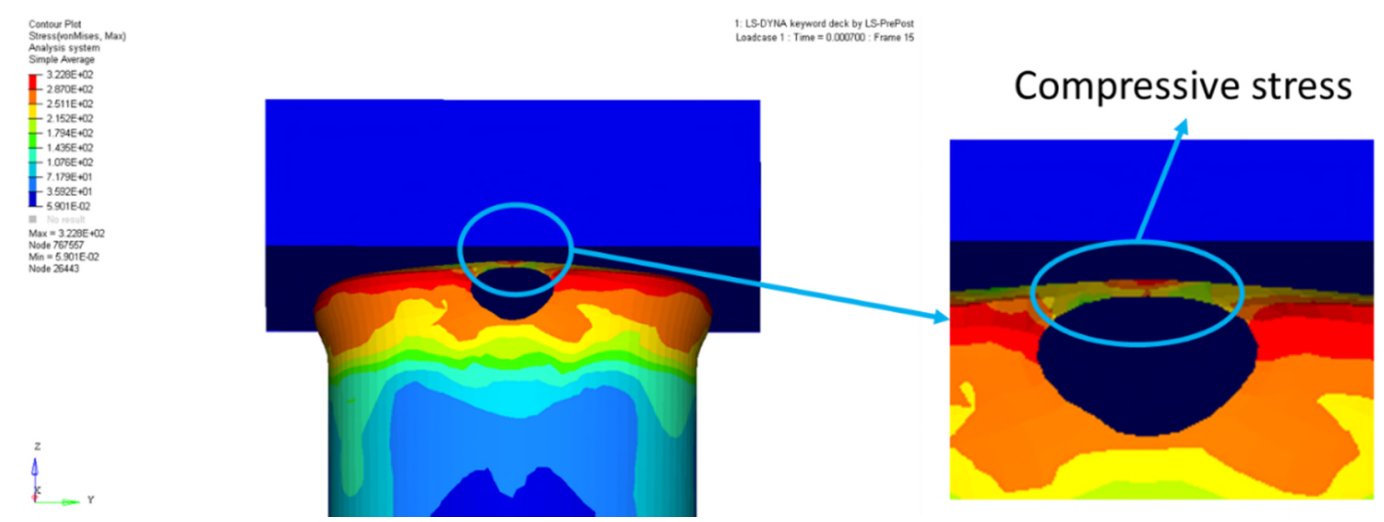

Figure 20 Compressive stress on the impact end (top end).

In order to evaluate the effect of the number of holes and obtain an optimum number of cutouts, $14 \mathrm{~mm}$ diameter holes wei rre placed at $10 \mathrm{~mm}$ from the impact end. Numerical simulations were carried out for impact on tubes by varying the number of cut-outs from one 
to six. Initial peak force and mean crushing forces were calculated and plotted against the number of cut-out holes as shown in Figure 21.

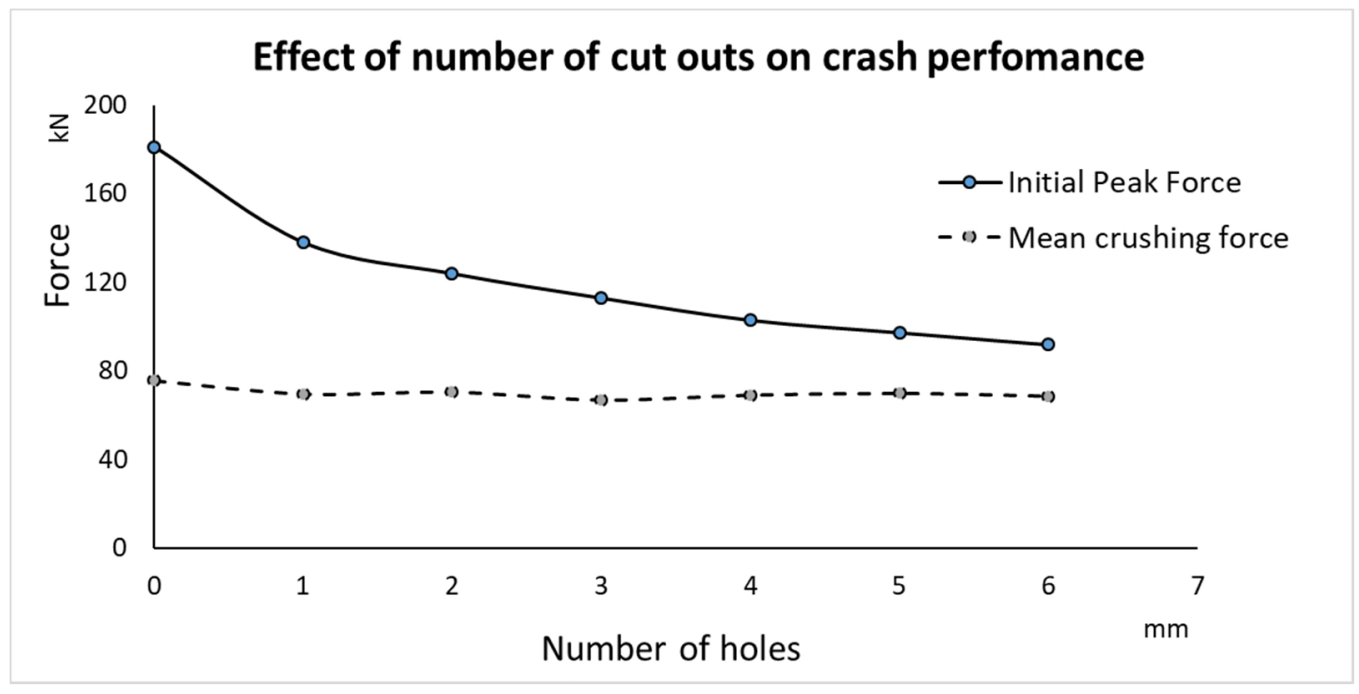

Figure 21 Effect of number of cut out holes on initial peak force and mean crushing force.

The general trend showed a decrease in initial peak force with an increase in the number of holes and an almost constant mean crushing force. Even though there is a decrease in initial force with a single hole, the crushing mechanism is not stable due to the asymmetric nature of the design. With two holes crushing of the tubes started with two circumferential lobes. Since it was not a very stable collapse mode, eventually it got shifted to 3 circumferential lobes. A very stable collapse mode with three circumferential lobes was observed when a trigger mechanism with three cut-out holes was used. Collapse mode with a trigger mechanism with four cut out holes was a diamond mode with four circumferential lobes initially, and later, it got shifted to three lobes. Hence it may have a stability issue. With more than four holes as a trigger mechanism, collapse mode observed was a mixed mode. So, based on the stability of the collapse and value of initial peak force, a trigger mechanism with three cut out holes was chosen as an optimum one (see Figure 22). 


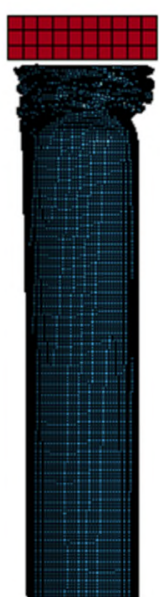

$\mathrm{N}=1$

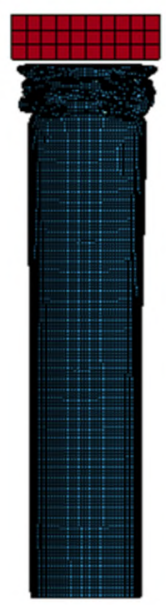

$\mathrm{N}=\mathbf{2}$

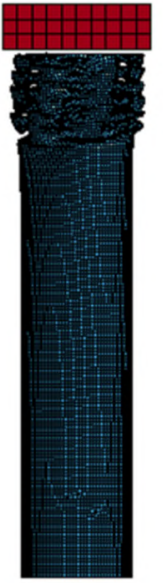

$\mathbf{N}=3$

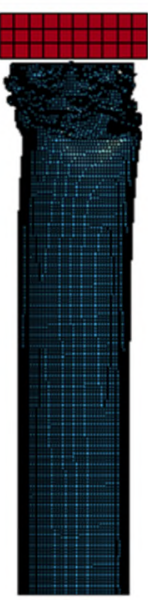

$\mathrm{N}=4$

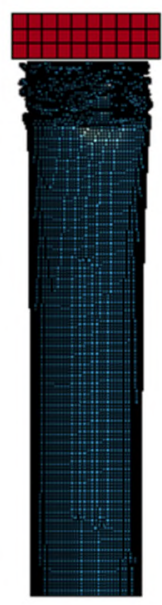

$\mathrm{N}=5$

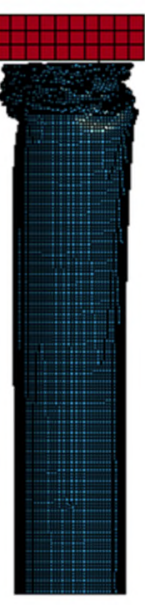

$N=6$

Figure 22 Deformed shapes of tubes along with number of cut out holes, $N$ (All the holes are positioned with the same distance from top of the tube and with equal distance between them).

Based on the above three studies, the optimum trigger mechanism consisting of circular cutouts has been finalised with parameters as shown in Table 3 and Figure 23.

Table 3 Optimum parameters for trigger mechanism consisting of holes.

\begin{tabular}{lcc}
\hline Parameters & \multicolumn{2}{c}{ Value } \\
\hline Number of holes & 3 & \\
Diameter of holes & 14 & $\mathrm{~mm}$ \\
$\begin{array}{l}\text { Location of hole centre } \\
\text { from impact end }\end{array}$ & 10 & $\mathrm{~mm}$ \\
\hline
\end{tabular}




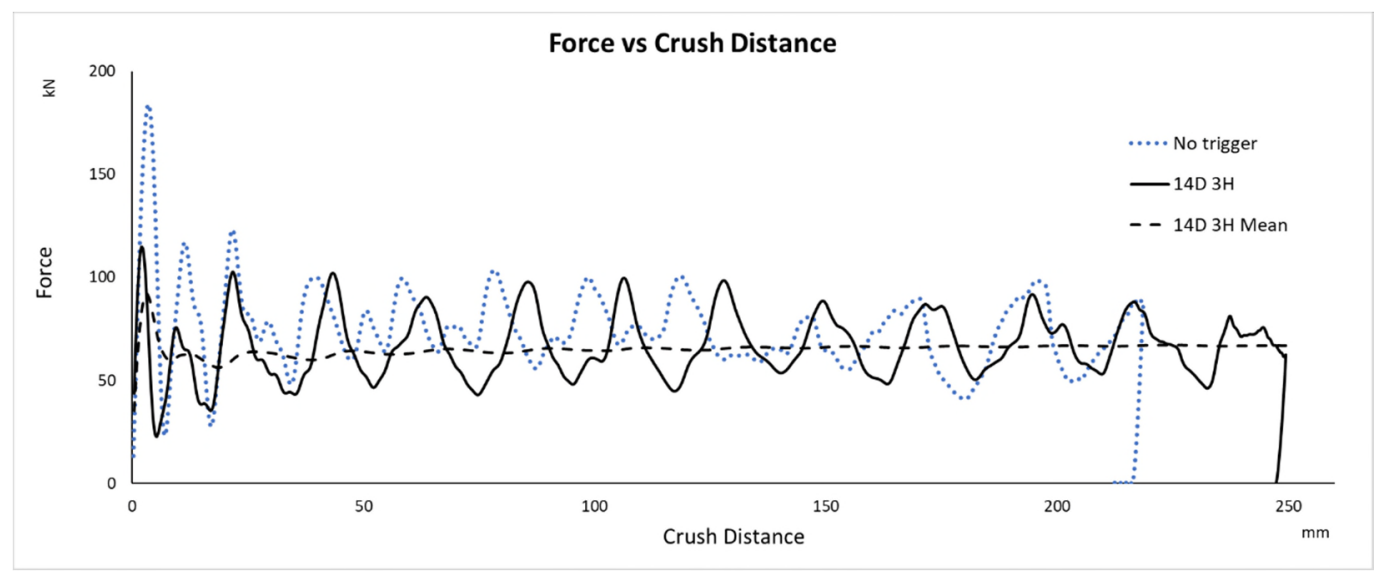

Figure 23 Force vs crush distance for tubes with three $14 \mathrm{~mm}$ holes as a trigger mechanism.

\subsubsection{End-fillet trigger mechanism}

An end fillet mechanism was introduced as a trigger mechanism to obtain collapse in a concertina mode (see Figure 24). The only parameter which was investigated in the end fillets was radius. In this regard, a series of numerical simulations were carried out on crash tubes by varying the fillet radius. A plot of initial peak force and mean crushing force is shown in Figure 25.

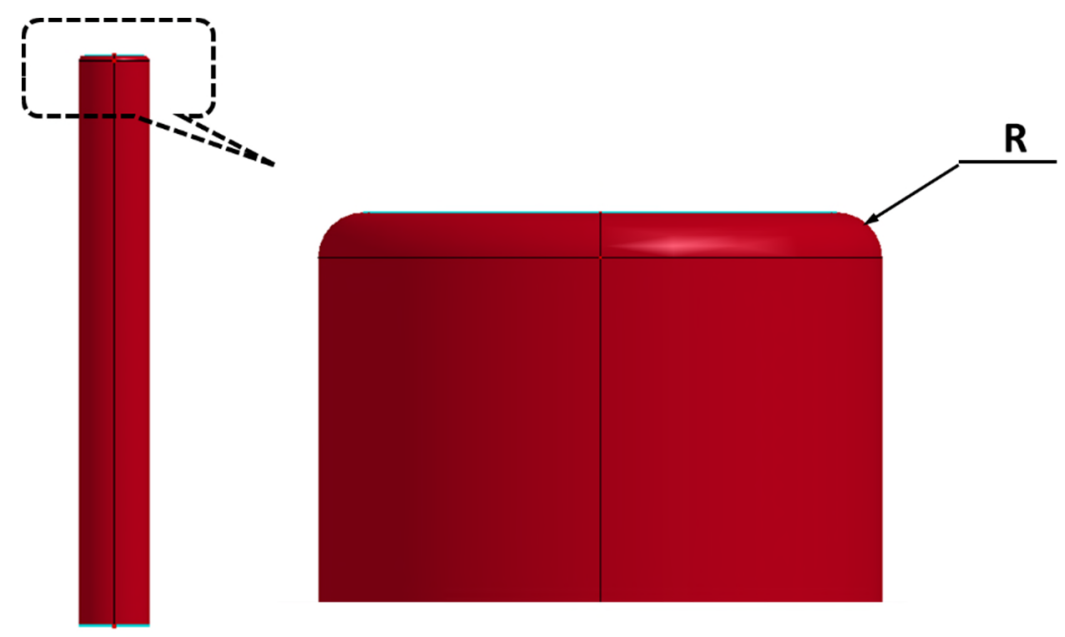

Figure 24 Details of the end fillet in tube absorber. 


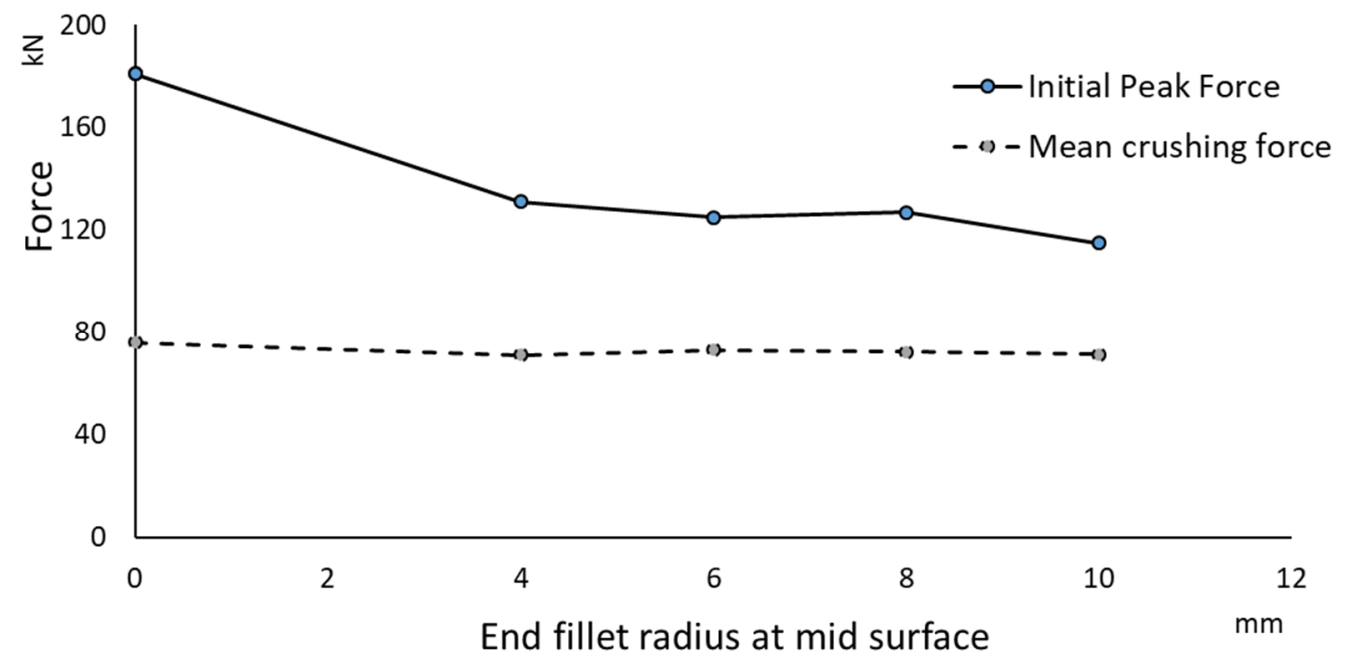

Figure 25 Effect of end fillet radius on initial peak force and mean crushing force.

A reduction in initial peak force was observed with the introduction of end fillet. However, a significant influence of the radius was not observed as the collapse mechanism was concertina mode for all values of the radius. Mean crushing force remained almost constant throughout and hence specific energy absorption. It is also worth considering that an end fillet with an inner radius less than the thickness of the tube is not possible to manufacture in a conventional manufacturing process. Hence, simulation was not carried out for an end fillet with a radius of the mid-surface $2 \mathrm{~mm}$ as it will lead to an inner radius less than $1.626 \mathrm{~mm}$, the thickness of the tube. Based on these studies, an end fillet radius of $6 \mathrm{~mm}$ was chosen for an optimum solution for this type of trigger mechanism. However, choice of the end fillet can be made based on the manufacturability as there is no significant effect on the crashworthiness performance. Force vs crush distance plots are shown in Figure 26.

\section{Force vs diplacement}

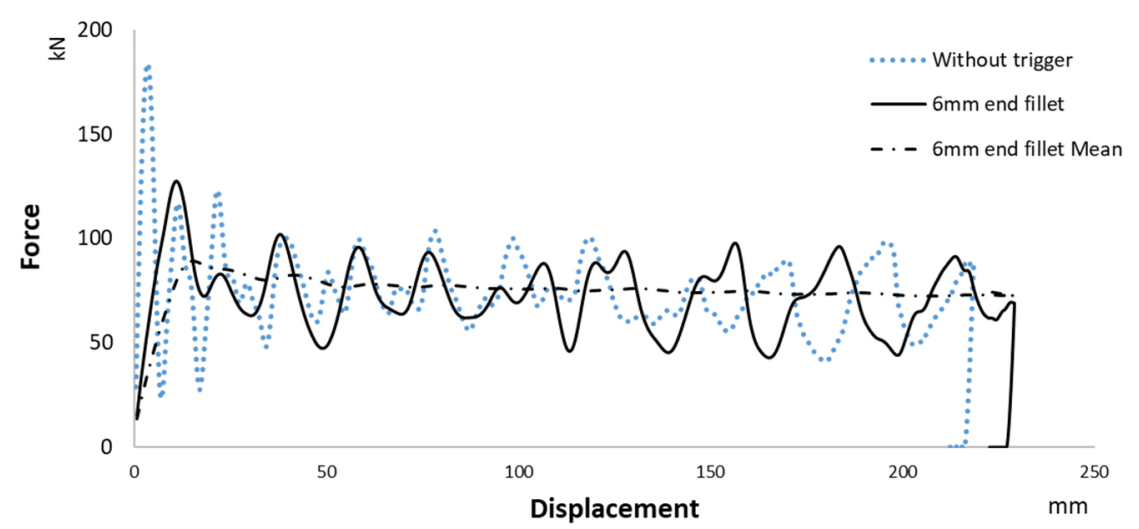

Figure 26 Force vs crush distance for tubes with a $6 \mathrm{~mm}$ radius end fillet as a trigger mechanism. 


\subsubsection{Circumferential trigger mechanism}

The shape of notch considered for this study was entirely different from the literature as shown in Figure 27. Radius of the notch and the fillet joining the notch to the cylinder were kept the same at the mid-surface to reduce the number of cases for numerical studies. Parameters of ' $R$ ', the radius and ' $H$ ', the location of the notch were investigated in this study.

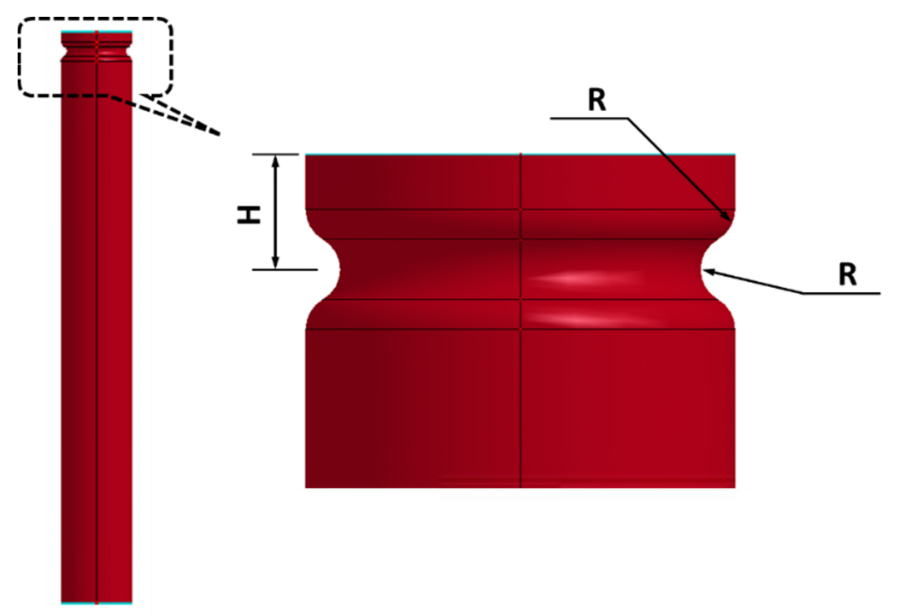

Figure 27 Details of the circumferential notch.

By fixing the location of the notch at $20 \mathrm{~mm}$ from the impact end, numerical simulations were carried out for crash tubes with different notch radii to study the effect of trigger mechanism. A plot of force vs crush distance obtained for radii varying from $4 \mathrm{~mm}$ to $10 \mathrm{~mm}$ as shown in Figure 28.

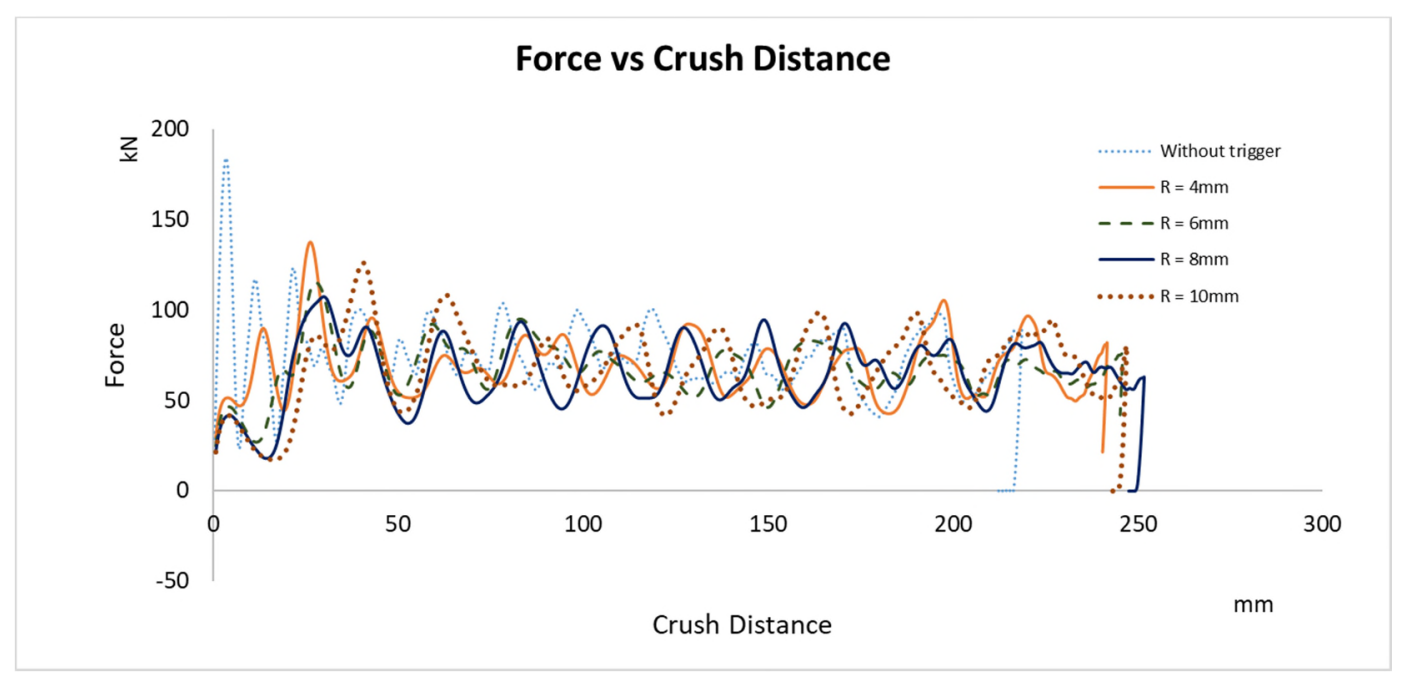

Figure 28 Force vs Crush Distance for circumferential notches with different radius.

The initial peak gets delayed by using circumferential notches as shown in Figure 29. It is mainly due to the natural collapse of the notch into a concertina lobe. After forming the first lobe, a higher peak force is required to form subsequent lobes as this first lobe does not form 
a trigger due to perfect symmetry. However, the initial peak force is lower than the one without the trigger (see Figure 29).

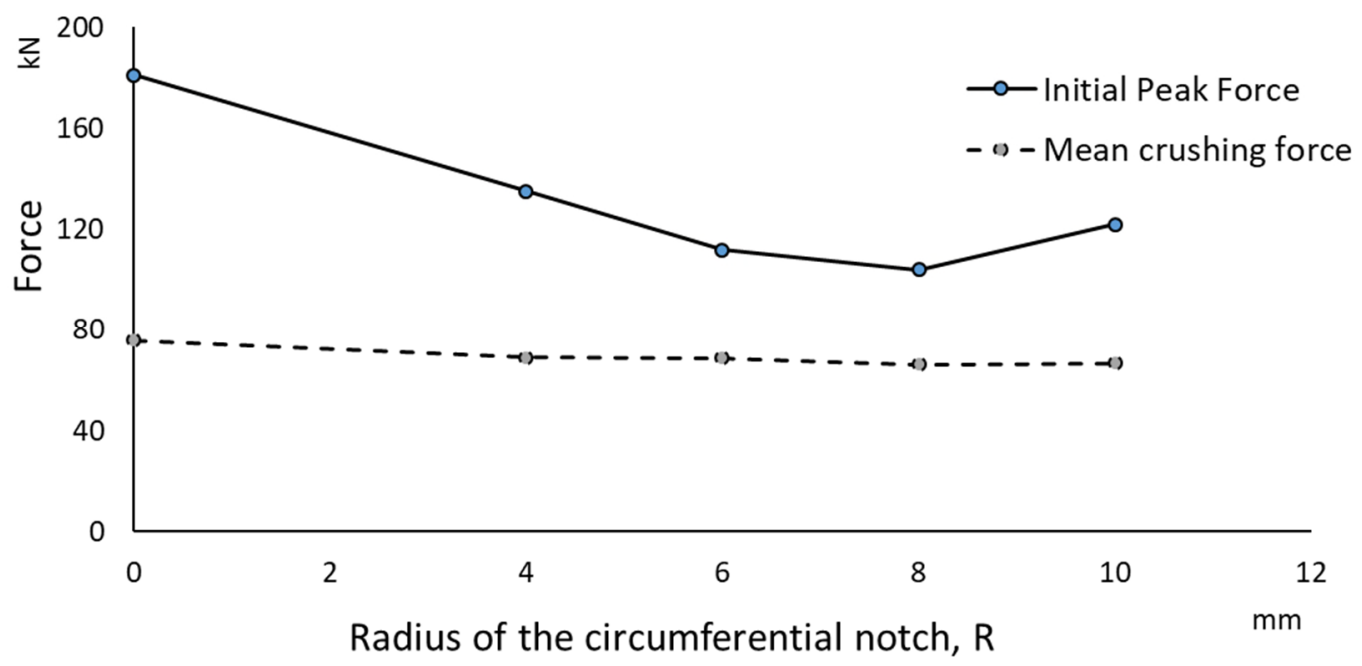

Figure 29 Initial and mean crushing forces for circumferential notches with different radii. Initial peak force decreased with an increase in the value of radius up to $8 \mathrm{~mm}$ only to surge at $10 \mathrm{~mm}$. In all the cases, initiation of the collapse was by crushing of the notch. The difference was observed in the subsequent stage, where the part of the tube above the notch bent inwards when the radius was less than or equal to $10 \mathrm{~mm}$, it remained undeformed as shown in Figure 30. An additional load path which was generated through the crushed part, increased the resistance for buckling, and hence a higher peak was observed for the notch with a $10 \mathrm{~mm}$ radius. Mean crushing force remains almost constant throughout the range. Moreover, hence crush force efficiency depends mainly on the initial peak force. Thus, a careful choice of the radius to be made to obtain a crash tube with optimum crashworthiness parameters.

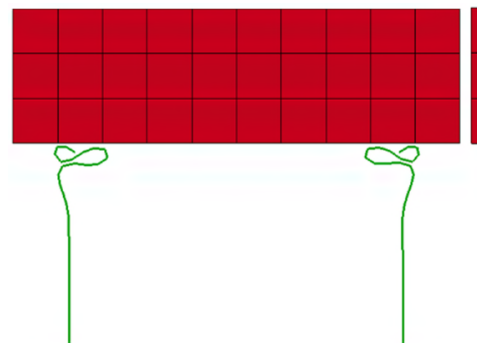

$\mathrm{R}=\mathbf{6} \mathrm{mm}$

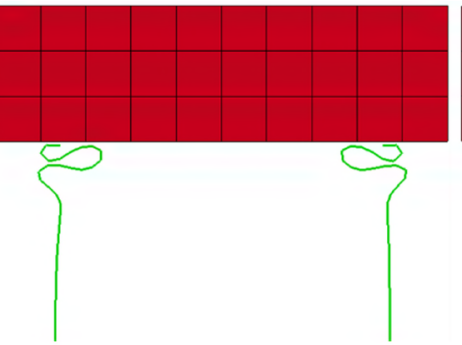

$\mathrm{R}=\mathbf{8} \mathrm{mm}$

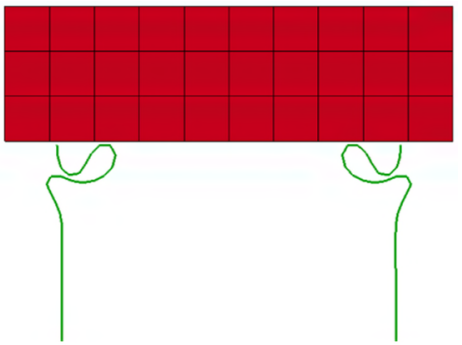

$\mathrm{R}=\mathbf{1 0} \mathrm{mm}$

Figure 30 Collapse mechanisms of tubes with circumferential notches with different radius.

A circumferential notch with $5 \mathrm{~mm}$ radius was placed at different locations, and numerical simulations were carried out to understand the effect of the location of the circumferential notch. In general, the initial peak remained the same for all the cases except when the distance 
between the notch and impact end was $20 \mathrm{~mm}$. A higher initial peak force was observed at a later stage as shown in Figure 31.

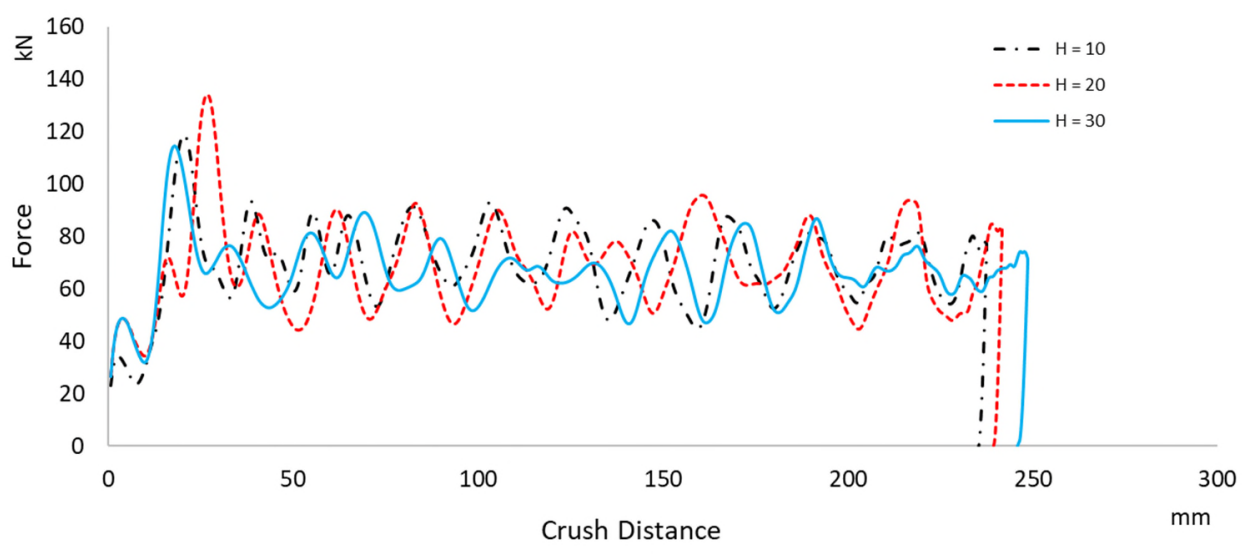

Figure 31 Force vs Crush Distance for circumferential notches at different locations.

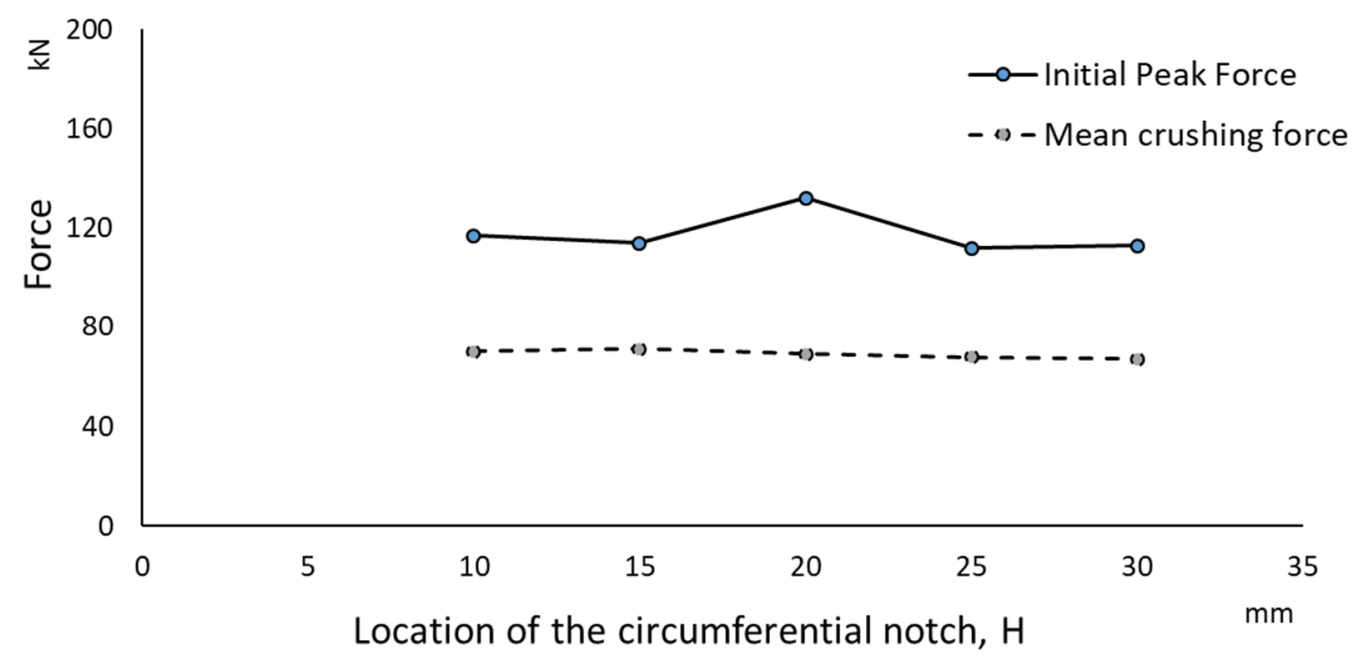

Figure 32 Force vs Crush Distance for circumferential notches at different locations.

Figure 32 shows a plot of initial peak force and mean crushing force concerning the position effects. Mean crushing force remained constant for all the cases. An abnormal increase in the initial peak force $(H=20 \mathrm{~mm})$ can be explained by using FigureFigure 33. After crushing of the notch, when the notch was placed at a distance less than $20 \mathrm{~mm}$ from impact end, the top portion of the tube bent outwards and when it was higher than $20 \mathrm{~mm}$ an unstable collapse was formed due to the interaction between buckling of the tube above and below the notch. When the distance was $20 \mathrm{~mm}$, a ring-like structure formed to strengthen the tube and it also provided an additional load path through crushed part of the notch. 

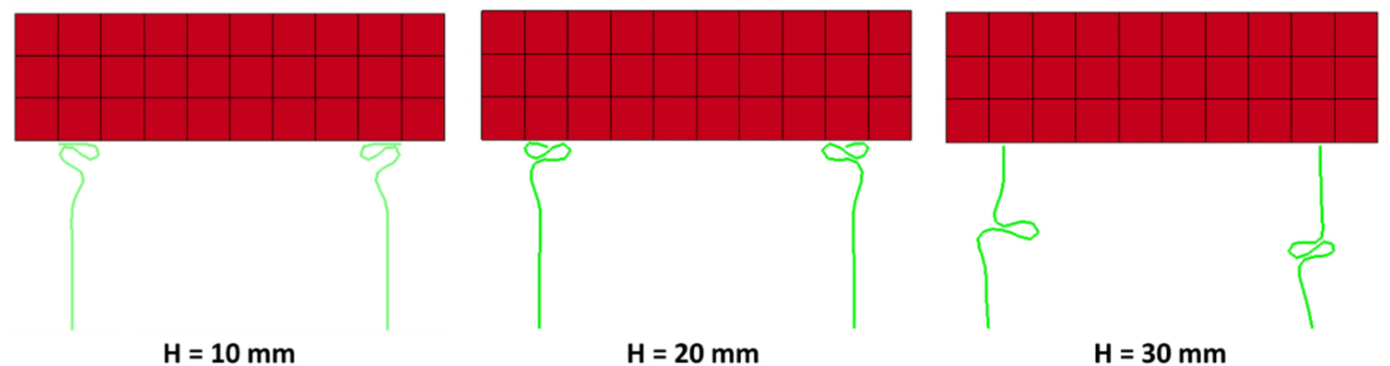

Figure 33 Collapse mechanisms of tubes with circumferential groves placed at different locations.

Based on these studies, it is evident that the radius and the location of the notches are not mutually exclusive parameters, but they have an interaction between them. Based on numerical simulations, a circumferential notch with $8 \mathrm{~mm}$ radius at $20 \mathrm{~mm}$ from the impact end is considered as an optimum solution. Force vs crush distance plot for this design is shown in Figure 34.

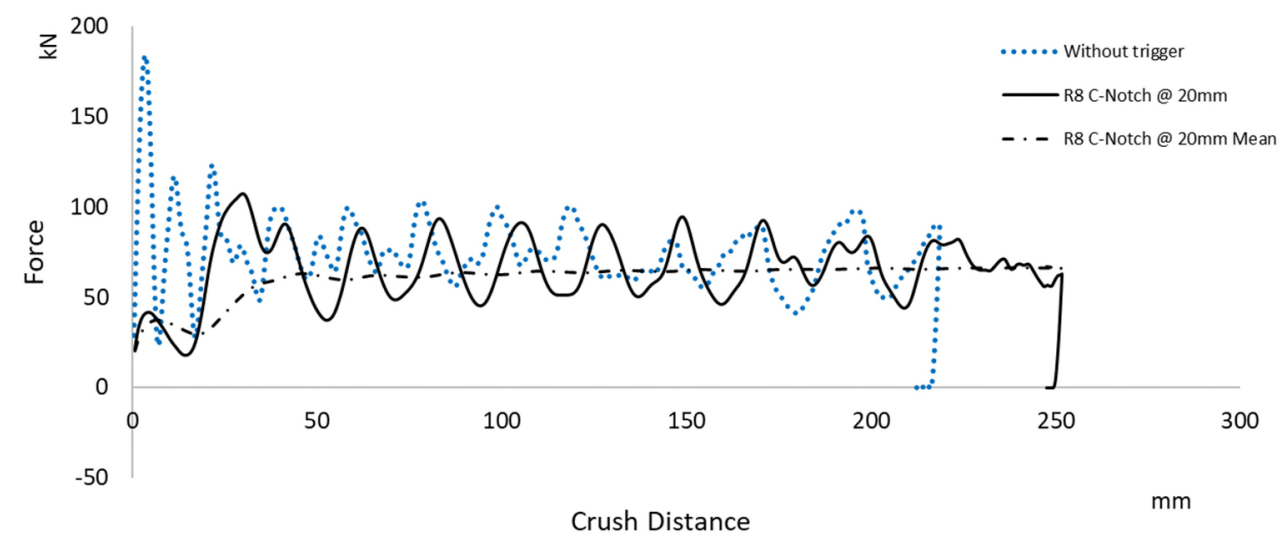

Figure 34 Force vs crush distance for tubes with circumferential groove of $8 \mathrm{~mm}$ radius placed at $20 \mathrm{~mm}$ from impact end as a trigger mechanism.

Finally, various trigger mechanism concepts were compared based on crashworthiness performance indicators, to choose the best concept among the ones discussed (see Figure 35). Trigger mechanism consisting of an end fillet of $6 \mathrm{~mm}$ showed better stroke efficiency and specific energy absorption in comparison with other cases. This is mainly due to starting of the collapse in a concertina mode. The circumferential notch had lowest specific energy absorption and highest crush force efficiency. The one with cut-out holes displayed a balanced performance among all three indicators and had a most stable collapse mechanism. Therefore, it was chosen as an optimum solution. As the main aim of this research has been based on improvement of crush force efficiency (CFE) with respect to SEA, the cut-out holes were selected as an efficient trigger mechanism among all three proposed designs. 


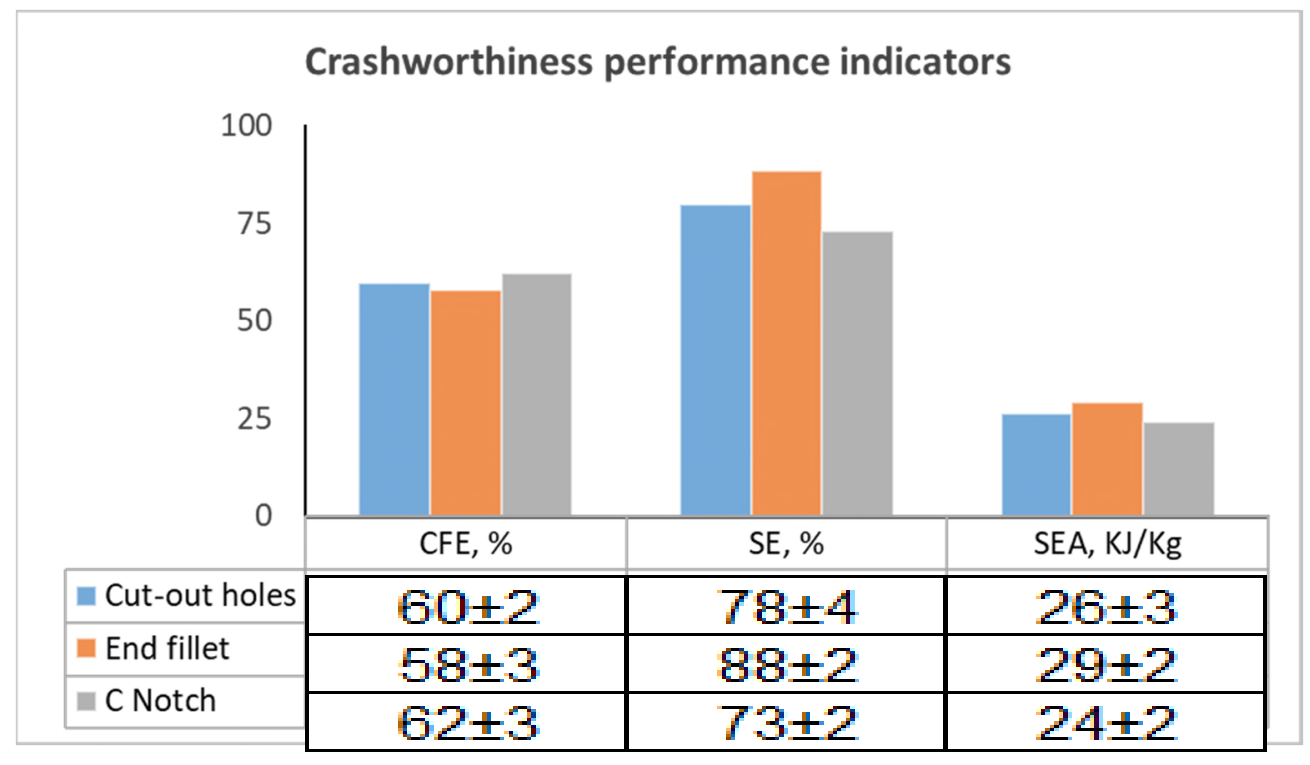

Figure 35 Comparison of trigger mechanisms.

Though the entire process was based on validated numerical simulations, it is necessary to verify the result with physical tests (see Figure 36 ). Holes were drilled by using progressive drilling technique for better positional accuracy. Deburring was done to ensure no stress concentration due to the manufacturing process. A plot of force vs crush distance obtained is shown in Figure 36 with CFC60 filter.

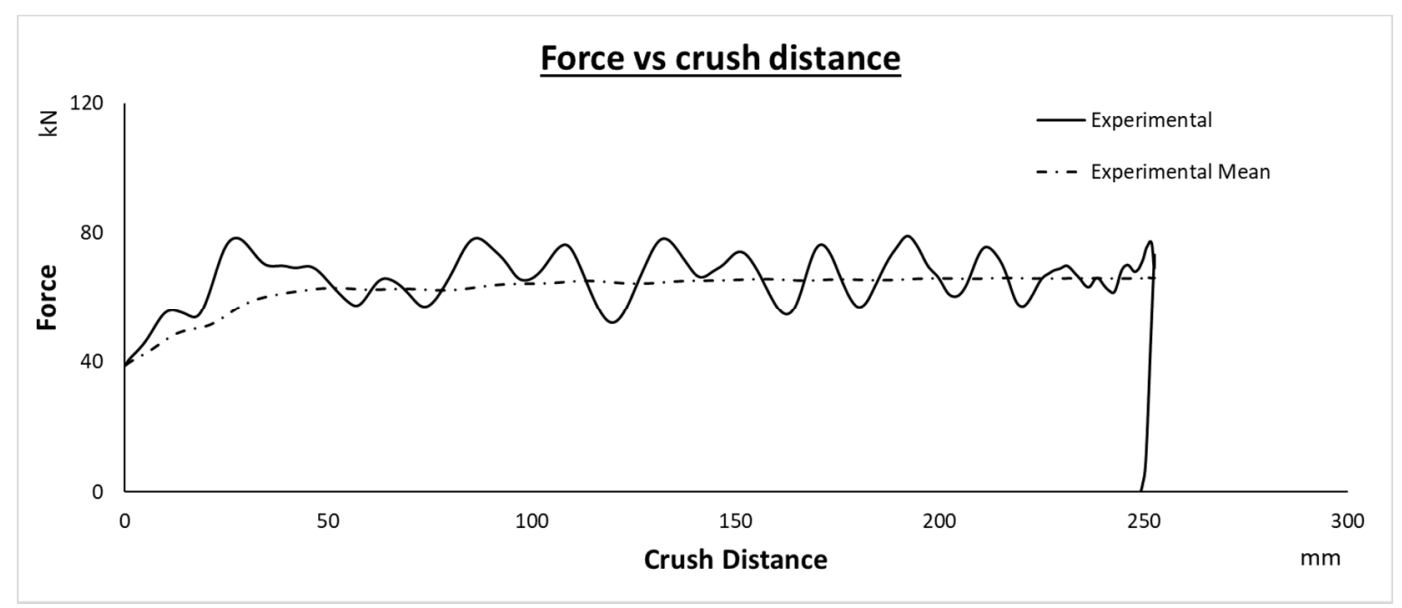

Figure 36 Force vs crush distance in the impact test - two tubes.

Force vs crush distance plot shows a gradual increase in load to a peak value of $77 \mathrm{kN}$. During the formation of subsequent lobes, the load was oscillating about a mean value of $65 \mathrm{kN}$. The calculated value of crash force efficiency is $84 \%$ (see Figure 37 ). 


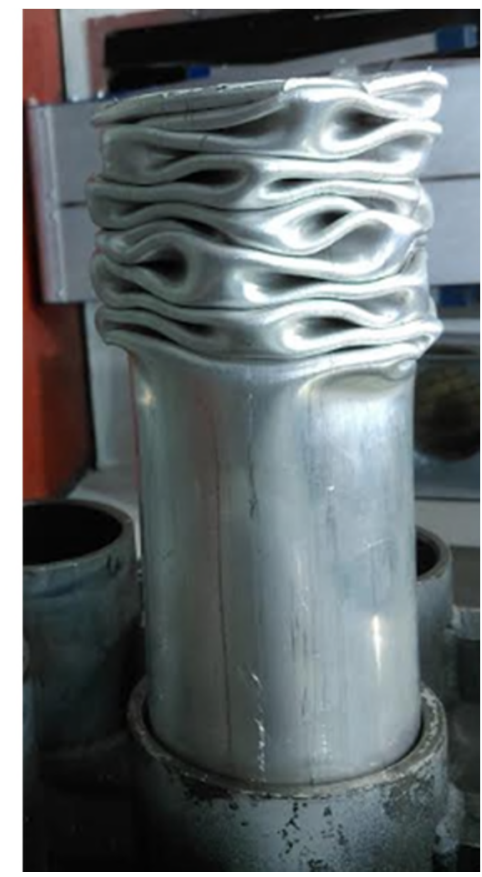

Figure 37 Deformed shape of the crash tube obtained in static and dynamic tests (Dimensions given in Table 1).

Crashworthiness performance indicators were calculated as CFE $=84, \mathrm{SE}=75$ and SEA $=$ $24 \mathrm{~kJ} / \mathrm{Kg}$. Numerical simulations provided a good insight on deformation of tubes during a crash event and were very useful in developing an optimum solution; however, it still has its limitations in predicting exact behaviour of the tube with any given trigger mechanism. Figure 37 shows a comparison of numerical and experimental results. Numerical results underpredict the initial peak force by $9.4 \%$. However, the error in mean crushing force prediction is only $2 \%$. The collapse mechanism predicted by the numerical simulations matches precisely with the experiment, and the same can be observed in Figures 38 and 39.

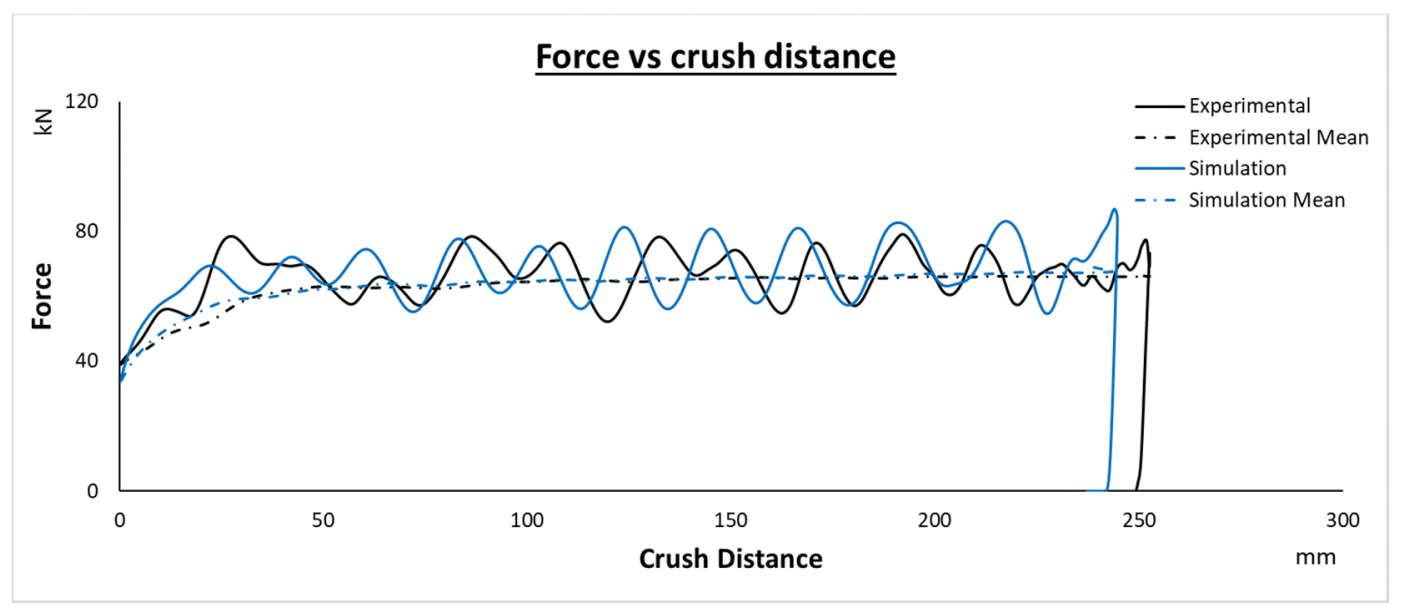

Figure 38 Comparison of numerical and experimental force vs crush distance plots for two crash tubes with three circular holes as a trigger mechanism. 

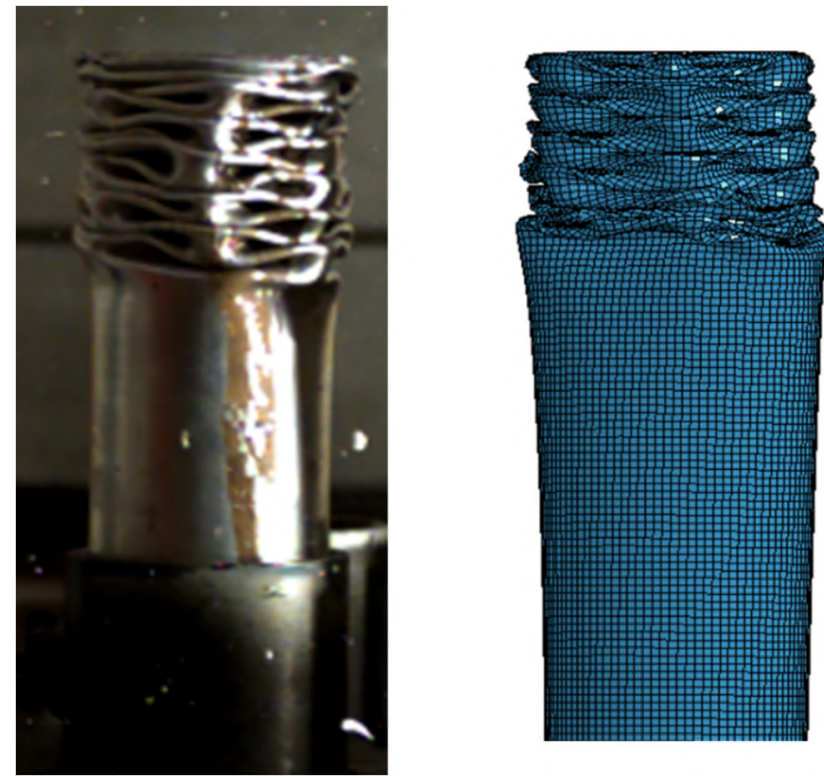

Figure 39 Deformed shape of the crash tube obtained in the experiment and numerical simulation.

Performance comparison of crash tubes with and without the trigger mechanism is shown in Figure 40.

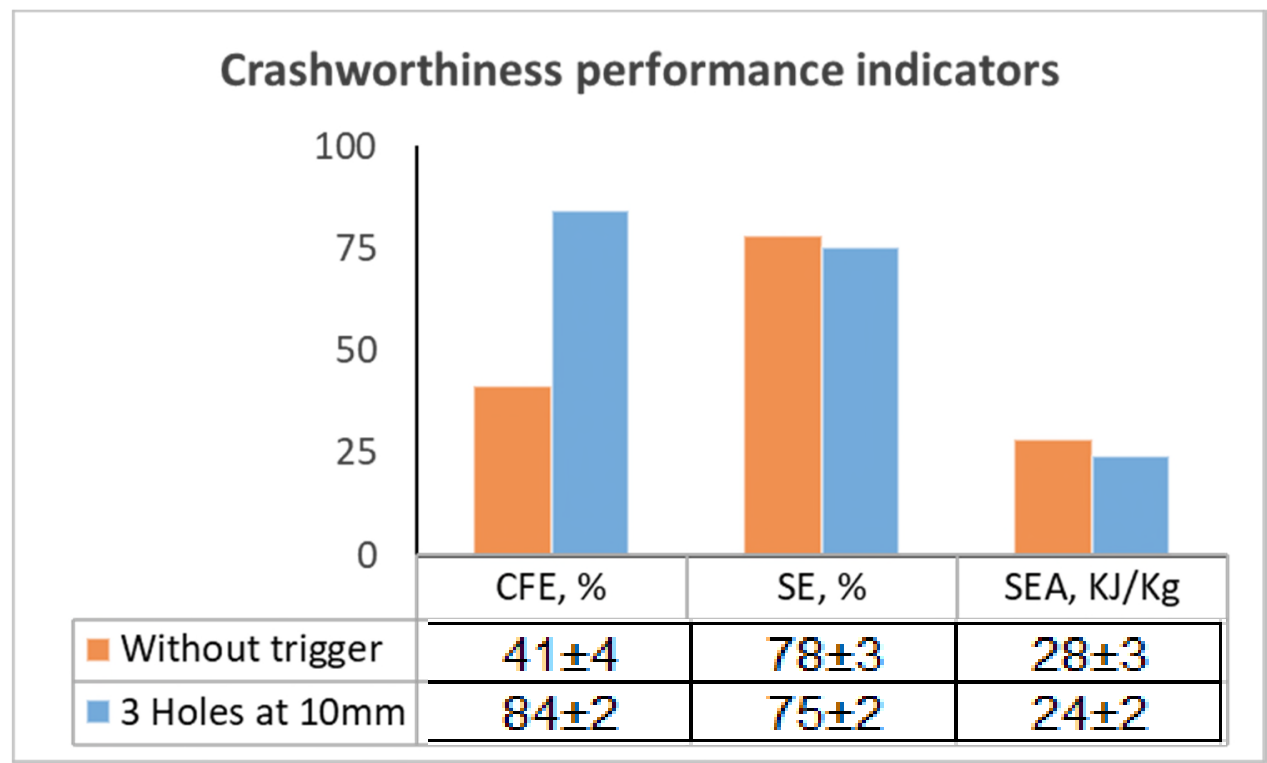

Figure 40 Comparison of performance of Aluminium crash tubes with and without a trigger mechanism.

\section{Conclusions}

Crashworthiness of circular tubes made up of Aluminium were studied with and without a trigger mechanism. A validated numerical model for simulation was obtained with the help of 
an experiment for both Aluminium and Steel tubes. Various trigger mechanisms were chosen for investigations, and optimum parameters were obtained for cut-out holes, end fillets and circumferential notches as a trigger mechanism. A comparative study was made between different trigger mechanisms and the one with cut-out holes was chosen as the best crashworthiness performance indicators.. Experimental validation of the chosen trigger mechanism was carried out, and comparable results were obtained in terms of performance indicators. A 104\% increase in crash force efficiency was observed, while a decrease in stroke efficiency and specific energy absorption were $4 \%$ and $15 \%$ respectively. Moreover, a very stable collapse mechanism was obtained by using a trigger mechanism. Therefore, It is essential to use an optimum trigger mechanism in a crash absorber to obtain lower initial peak force and ensure a stable collapse process in comparison with the existing designs.

\section{References}

[1] 'Global Status Report on Road' (2015).

[2] Goel, M. D. (2016) 'Numerical investigation of the axial impact loading behaviour of single, double and stiffened circular tubes', International Journal of Crashworthiness. Taylor \& Francis, 21(1), pp. 41-50. doi: 10.1080/13588265.2015.1113617.

[3] Baroutaji, A., Sajjia, M. and Olabi, A. G. (2017) 'On the crashworthiness performance of thin-walled energy absorbers: Recent advances and future developments', Thin-Walled Structures. Elsevier Ltd, 118(November), pp. 137-163. doi: 10.1016/j.tws.2017.05.018.

[4] Jones, N. (2003) 'Several phenomena in structural impact and structural crashworthiness', European Journal of Mechanics, A/Solids, 22(5), pp. 693-707. doi: 10.1016/S09977538(03)00077-9.

[5] Balandin, D. V., Bolotnik, N. N., Pilkey, W. D. and Purtsezov, S. V. (2005) 'Optimal Control Problem for Head Injury Criterion', Proceedings. 2005 International Conference Physics and Control, 2005., (2), pp. 130-133. doi: 10.1109/PHYCON.2005.1513964.

[6] EuroNCAP (2011) 'European New Car Assessment Programme (Euro NCAP) Assessment Protocol - Adult occupant protection', (June), p. 28. Available at: http://www.euroncap.com/en.

[7] Tarlochan, F., Samer, F., Hamouda, A. M. S., Ramesh, S. and Khalid, K. (2013) 'Design of thin wall structures for energy absorption applications : Enhancement of crashworthiness 
due to axial and oblique impact forces Thin-Walled Structures Design of thin wall structures for energy absorption applications : Enhancement of crashworthi', Thin Walled Structures, 71, pp. 7-17. doi: 10.1016/j.tws.2013.04.003.

[8] Lu, S. (2014) 'Impact Energy Absorption Analysis of Different Thin-Walled Tubes With and Without Reinforcement 2014'.

[9] Ghasemnejad, H., Hadavinia, H., Marchant, D. and Aboutorabi, A. (2008) 'Energy absorption of thin-walled corrugated crash box in axial crushing', SDHM Structural Durability and Health Monitoring, 4(1).

[10] Saboori, P. and Sadegh, A. M. (2018) 'IMECE2013-65125 Evaluation of Head Injury Criteria under Different Impact Loading', (1), pp. 1-6.

[11] Li, Z., Yang, H., Hu, X., Wei, J. and Han, Z. (2018) 'Experimental study on the crush behavior and energy-absorption ability of circular magnesium thin-walled tubes and the comparison with aluminum tubes', Engineering Structures. Elsevier, 164(September 2017), pp. 1-13. doi: 10.1016/j.engstruct.2018.02.083.

[12] Nia, A. A. and Hamedani, J. H. (2010) 'Comparative analysis of energy absorption and deformations of thin walled tubes with various section geometries', Thin-Walled Structures. Elsevier, 48(12), pp. 946-954. doi: 10.1016/j.tws.2010.07.003.

[13] Santhosh Kumar, V. and Manikandaraja, G. (2016) 'Numerical study on energy absorbing characteristics of thin-walled tube under axial and oblique impact', Alexandria Engineering Journal, 55(1), pp. 187-192. doi: 10.1016/j.aej.2015.12.008.

[14] Ghamarian, A. and Tahaye Abadi, M. (2011) 'Axial crushing analysis of end-capped circular tubes', Thin-Walled Structures. Elsevier, 49(6), pp. 743-752. doi: 10.1016/j.tws.2011.01.006.

[15] Shakeri, M., Mirzaeifar, R. and Salehghaffari, S. (2007) 'New insights into the collapsing of cylindrical thin-walled tubes under axial impact load', Proceedings of the Institution of Mechanical Engineers, Part C: Journal of Mechanical Engineering Science, 221(8), pp. 869885. doi: 10.1243/09544062JMES562.

[16] Yuen, S. C. K. and Nurick, G. N. (2008) 'The Energy-Absorbing Characteristics of Tubular Structures With Geometric and Material Modifications: An Overview', Applied Mechanics Reviews, 61(2), p. 020802. doi: 10.1115/1.2885138. 
[17] Gupta, N. K. and Gupta, S. K. (1993) 'Effect of annealing, size and cut-outs on axial collapse behaviour of circular tubes', International Journal of Mechanical Sciences, 35(7), pp. 597-613. doi: 10.1016/0020-7403(93)90004-E.

[18] Gupta, N. K. (1998) 'Some aspects of axial collapse of cylindrical thin-walled tubes', Thin-Walled Structures, 32(1-3), pp. 111-126. doi: 10.1016/S0263-8231(98)00029-9.

[19] Toda, S. (1983) 'Buckling of cylinders with cutouts under axial compression', Experimental Mechanics, December(December), pp. 414-417. doi: doi:10.2514/6.1969-92.

[20] Chiu, Y. S. and Jenq, S. T. (2014) 'Crushing behavior of metallic thin-wall tubes with triggering mechanisms due to quasi-static axial compression', Journal of the Chinese Institute of Engineers, Transactions of the Chinese Institute of Engineers, Series A/Chung-kuo Kung Ch'eng Hsuch K'an, 37(4), pp. 469-478. doi: 10.1080/02533839.2013.800275.

[21] Montazeri, S., Elyasi, M. and Moradpour, A. (2018) 'Investigating the energy absorption, SEA and crushing performance of holed and grooved thin-walled tubes under axial loading with different materials', Thin-Walled Structures. Elsevier Ltd, 131(July), pp. 646-653. doi: 10.1016/j.tws.2018.07.024.

[22] Zhang, X. W., Tian, Q. D. and Yu, T. X. (2009) 'Axial crushing of circular tubes with buckling initiators', Thin-Walled Structures, 47(6-7), pp. 788-797. doi: 10.1016/j.tws.2009.01.002.

[23] Singace, A. A. and EI-Sobkey, H. (1997) 'B E H A V I O U R OF AXIALLY C R U S H E D C O R R U G A T E D TUBES', 39(3).

[24] Chen, D. H. and Ozaki, S. (2009) 'Circumferential strain concentration in axial crushing of cylindrical and square tubes with corrugated surfaces', Thin-Walled Structures, 47(5), pp. 547-554. doi: 10.1016/j.tws.2008.10.003.

[25] Käfer, B., Bheemineni, V. K., Lammer, H., Kotnik, M. and Riemelmoser, F. O. (2013) 'Effects of position and cut-out lengths on the axial crushing behavior of aluminum tubes: Experimental and simulation', International Journal of Mechanical, Aerospace, Industrial and Mechatronics Engineering, 7(11), pp. 1089-1096.

[26] Al, V. (2015) Varmint Al's Engineering Page. doi: 10.15713/ins.mmj.3.

[27] Yiru Ren Hongyong Jiang, Zhihui Liu, (2019) Evaluation of double- and triple-coupled triggering mechanisms to improve crashworthiness of composite tubes, International Journal 
of Mechanical Sciences, Volumes 157-158, July 2019, Pages 1-12.

[28] Hongyong Jiang, YiruRen, Binhua Gao, (2017) Research on the progressive damage model and trigger geometry of composite waved beam to improve crashworthiness ThinWalled Structures, Volume 119, October 2017, Pages 531-543.

[29] N Nasir Hussain, Srinivasa Prakash, Regalla, Yendluri V Daseswara Rao, (2017) Comparative Study of Trigger Configuration for Enhancement of Crashworthiness of Automobile Crash Box Subjected to Axial Impact Loading, Procedia Engineering, Volume 173, 2017, Pages 1390-1398.

[30] Sidun, P. and Łukaszewicz, A. (2017) 'Verification of Ram-Press Pipe Bending Process using Elasto-Plastic FEM Model', Acta Mechanica et Automatica, 11(1), pp. 47-52. doi: 10.1515/ama-2017-0007.

[31] Abdollahpoor, A. and Marzbanrad, J. (2010) 'Crashworthiness study of axial impact in cylindrical aluminium tubes', (January 2015), p. 2010.

[32] Noversa, M. and Peixinho, N. (2013) 'Numerical Simulation of Impact Behaviour of Structures with Internal Pressurization for Crash-Adaptive Concept', pp. 185-195.

[33] Fyllingen, O., Hopperstad, O. S., Hanssen, A. G. and Langseth, M. (2010) 'Modelling of tubes subjected to axial crushing', Thin-Walled Structures. Elsevier, 48(2), pp. 134-142. doi: 10.1016/j.tws.2009.08.007.

[34] Al Galib, D. and Limam, A. (2004) 'Experimental and numerical investigation of static and dynamic axial crushing of circular aluminum tubes', Thin-Walled Structures, 42(8), pp. 1103-1137. doi: 10.1016/j.tws.2004.03.001.

[35] Al Galib, D. and Limam, A. (2004) 'Experimental and numerical investigation of static and dynamic axial crushing of circular aluminum tubes', Thin-Walled Structures, 42(8), pp. 1103-1137. doi: 10.1016/j.tws.2004.03.001.

[36] Ibrahim, H. K. (2009) 'Design Optimization of Vehicle Structures for Crashworthiness Improvement', (August).

[37] Marzbanrad, J. and Ebrahimi, M. R. (2011) 'Multi-Objective Optimization of aluminum hollow tubes for vehicle crash energy absorption using a genetic algorithm and neural networks', Thin-Walled Structures, 49(12), pp. 1605-1615. doi: 10.1016/j.tws.2011.08.009. 
[38] Zarei, H. R. and Kröger, M. (2006) 'Multiobjective crashworthiness optimization of circular aluminum tubes', Thin-Walled Structures, 44(3), pp. 301-308. doi: 10.1016/j.tws.2006.03.010.

[39] Abramowicz, W. and Jones, N. (1986) 'Dynamic progressive buckling of circular and square tubes', International Journal of Impact Engineering, 4(4), pp. 243-270. doi: 10.1016/0734-743X(86)90017-5.

[40] Hsu S.S. and Jones N. (2004) 'Quasi-static and dynamic axial crushing of thin-walled circular stainless steel, mild steel and aluminium alloy tubes', International Journal of Crashworthiness, 9(2), pp. 195 - 217, doi:10.1533/ijcr.2004.0282. 
2019-09-11

\section{Developed trigger mechanisms to improve crush force efficiency of aluminium tubes}

Rai, V.

Elsevier

Rai V, Ghasemnejad H, Watson JW, et al., (2019) Developed trigger mechanisms to improve crush force efficiency of aluminium tubes. Engineering Structures, Volume 199, November 2019, Article number 109620

https://doi.org/10.1016/j.engstruct.2019.109620

Downloaded from Cranfield Library Services E-Repository 